\title{
Highly porous polycaprolactone scaffolds doped with calcium silicate and dicalcium phosphate dihydrate designed for bone regeneration
}

Maria Giovanna Gandolfi ${ }^{1 *}$, Fausto Zamparini ${ }^{1,2}$, Micaela Degli Esposti ${ }^{3}$, Federica Chiellini ${ }^{4}$, Fabio Fava $^{3}$, Paola Fabbri ${ }^{3}$, Paola Taddei ${ }^{5}$, Carlo Prati ${ }^{2}$

1 Laboratory of Biomaterials and Oral Pathology, School of Dentistry, Department of Biomedical and Neuromotor Sciences, University of Bologna, Bologna, Italy

2 Endodontic Clinical Section, School of Dentistry, Department of Biomedical and Neuromotor Sciences, University of Bologna, Bologna, Italy

3 Department of Civil, Chemical, Environmental and Materials Engineering, University of Bologna, Bologna, Italy 4 BIOlab Research Group, Department of Chemistry and Industrial Chemistry, University of Pisa, Pisa, Italy

5 Biochemistry Unit, Department of Biomedical and Neuromotor Sciences, University of Bologna, Bologna, Italy

Corresponding author: Maria Giovanna Gandolfi. Laboratory of Biomaterials and Oral Pathology, Dental School, University of Bologna, Via San Vitale 59, 40125 - Bologna, Italy tel. +39 0512088176 . Fax: +39 051 225208. email:mgiovanna.gandolfi@unibo.it 


\begin{abstract}
Polycaprolactone (PCL), dicalcium phosphate dihydrate (DCPD) and/or calcium silicates (CaSi) have been used to prepare highly porous scaffolds by thermally induced phase separation technique (TIPS). Three experimental mineral-doped formulations were prepared (PCL-10CaSi, PCL-5CaSi-5DCPD, PCL-10CaSi10DCPD); pure PCL scaffolds constituted the control group.
\end{abstract}

Scaffolds were tested for their chemical-physical and biological properties, namely calcium release, alkalinizing activity, surface microchemistry and micromorphology by Environmental Scanning electronic Microscopy (ESEM), apatite-forming ability in Hank's Balanced Salt Solution (HBSS) by Energy Dispersive X-Ray Spectroscopy (EDX) and micro-Raman, thermal properties by differential scanning calorimetry, mechanical properties by quasi-static parallel-plates compression testing, porosity by a standard waterabsorption method and direct contact cytotoxicity.

All mineral-doped scaffolds released calcium and alkalinized the soaking medium, which may favor a good biological (osteogenic) response.

ESEM surface micromorphology analyses after soaking in HBSS revealed: pure PCL, PCL-10CaSi and PCL-10CaSi-10DCPD kept similar surface porosity percentages but different pore shape modifications. PCL-5CaSi-5DCPD revealed a significant surface porosity increase despite calcium phosphates nucleation $(\mathrm{p}<0.05)$.

Micro-Raman spectroscopy detected the formation of a B-type carbonated apatite layer on the surface of PCL-10CaSi-10DCPD aged for 28 days in HBSS; a similar phase (but of lower thickness) formed also on PCL-5CaSi-5DCPD and PCL; the deposit formed on PCL-10CaSi was mainly composed of calcite.

All PCL showed bulk open porosity higher than 94\%; however, no relevant brittleness was observed in the materials, which retained the possibility to be handled without collapsing.

The thermo-mechanical properties showed that the reinforcing and nucleating action of the inorganic fillers CaSi and DCPD improved viscoelastic properties of the scaffolds, as confirmed by the increased value of storage modulus and the slight increase in the crystallization temperature for all the biomaterials.

A detrimental effect on the mechanical properties was observed in samples with the highest amount of inorganic particles (PCL-10CaSi-10DCPD).

All the scaffolds showed absence of toxicity, in particular PCL-10CaSi-10DCPD.

The designed scaffolds are biointeractive (release biologically relevant ions), nucleate apatite, possess high surface and internal open porosity and can be colonized by cells, creating a bone forming osteoblastic microenvironment and appearing interesting materials for bone regeneration purposes.

Keywords: porous scaffold; polycaprolactone; calcium silicate; calcium phosphate; bone regeneration; thermally induced phase separation. 


\section{Introduction}

Trauma, tumor resection, infections and disease frequently result in critical sized bone defects (unable to heal spontaneously) or fractures in cranio-maxillo-facial, oral and orthopedic districts [1]. Management of these worldwide diseases necessitates predictable bone grafting or major surgical reconstruction.

Gold standard autologous bone graft for oral and maxillofacial surgery has not a predictable outcome, particularly when the host possesses a compromised immune response and lowered/decreased bone healing [2]. Furthermore, autologous bone graft does not ensure a predictable regenerating bone volume and requires further autograft bone harvesting with additional co-morbidities and higher costs [2].

A great number of materials currently marketed as bone substitutes are not bioactive, not osteoinductive and with high risks for bacterial suprainfections. There is an increasing trend to utilize non-metallic materials such as polymers, ceramics and composites rather than metals [3].

The use of biocompatible slow-resorbing porous scaffolds where stem cells can migrate, grow and differentiate into bone mineralizing cells, represent an interesting approach for tissue engineering.

Polycaprolactone (PCL) is a semicrystalline linear aliphatic polyester widely used for biomedical application, such as orthopaedic screws, drug delivery devices [11] and scaffolds for bone tissue engineering [12]. PCL may be obtained by either ring opening polymerization of $\varepsilon$-caprolactone using a variety of anionic, cationic and co-ordination catalysts or via free radical ring-opening polymerization of 2-methylene1,3-dioxepane [13]. Re-emergence of this polymer in the biomedical field is related to the good processability, compatibility with different polymers, broad molecular weight range, solubility in common organic solvents and the possibility to tailor its mechanical properties [14]. Moreover its long bioresorption time ( 2 years) may be useful in tissue engineering procedures [15]. On the other hand, PCL suffers from drawbacks due to its intrinsic hydrophobic chemical nature, its poor surface wettability and interaction with biological fluids, limiting/hampering cells adhesion and proliferation [13]. To overcome its drawbacks, PCL composites were produced by adding inorganic phases, such as hydroxyapatite [16,17].

Biointeractivity with the local environment - i.e. capability to exchange of information between a biological system and capability of sending and/or receiving information from a living organism [PAS 2007] - is another interesting requisite for a scaffold providing biological advantages.

Hydraulic Calcium Silicate Cements (HCSC) are attractive materials for their release of biologically relevant ions (biointeractivity) [46], antibacterial activity and capability to nucleate apatite (bioactivity) [4] and support the growth and differentiation of human orofacial mesenchymal stem cells [Gandolfi 2011], human marrow stromal cells [Gandolfi 2010] and pulp cells [8]. These properties justified their wide application in dentistry as materials to be placed in close vicinity to pulp or bone tissue $[4,5]$. Nowadays, 
HCSC are used in several dental applications: in endodontics as root canal sealers [6], as root-end filling materials [7], for direct pulp capping [8] and as mineral filler in scaffolds for bone regeneration [9]. The incorporation of Calcium phosphates, such as dicalcium phosphate dehydrate (DCPD) further improves apatite-forming ability of HCSC, as previously demonstrated [10].

Several techniques have been developed to produce scaffolds for tissue engineering, including electrospinning technique [12], 3D printing [18], salt leaching [19] and thermally induced phase separation (TIPS) $[9,20]$. TIPS procedure allows the preparation of highly porous $(>90 \%)$ scaffolds without the need of high temperatures that may alter the properties of the polymer matrix or those of the mineral filler [9].

Porosity is a key factor to be considered when approaching tissue regeneration. Numerous attempts to produce highly porous scaffolds by several techniques and different materials are reported in literature. Polylactic-based scaffolds enriched with $20 \%$ beta tricalcium phosphates produced by salt leaching technique reaching a porosity of $87 \%$, were tested for cranial defects in rabbits showing optimal bone ingrowth [Roy 2003]. Composite sponges made of polylactic co glycolic, collagen and apatite particulates were produced by sintering, reaching porosity values of $87 \%$ [Chen 2000]. Despite there is no consensus regarding the optimal pore sizes, porosity values and percentage of interconnected pores in literature [Karageorgiou 2005], however high porosity values (over 90\%) are beneficial for bone tissue engineering [20, Chen 2000, Roy 2003, Amini 2012], with the result of higher cell proliferation, enhanced bone ingrowth and osteogenesis processes [Karageorgiou 2005], which is attributable to the greater transport of oxygen and nutrients [Feng 2011].

Considering the potentiality of TIPS to produce highly porous PCL scaffolds [Fabbri 2010] together with the biological properties of HCSC [4,5,8 Gandolfi 2010, 2011] it should be interesting to produce by TIPS highly porous PCL-based scaffolds doped with HCSC with/without DCPD for maxillofacial bone regeneration. To date, no similar scaffolds have been proposed.

Therefore, the aim of this study was to fabricate bioactive biointeractive highly porous PCL-based scaffolds doped with different amounts of HCSC and/or DCPD mineral powders at low temperature by using TIPS technique. The experimental scaffolds were tested for physical-mechanical properties, surface microchemistry and micromorphology, ion release and alkalinizing activity, calcium phosphate nucleation, and direct-contact cytotoxicity.

\section{Material and methods}

\subsection{Materials}

Methanol (MeOH), ethanol (EtOH, 99.8\%), 1,4-dioxan (DIOX) and chloroform (CHCl3, HPLC grade) all from Sigma Aldrich (Milan, Italy) were used as received without further purification. Polycaprolactone (PCL, average Mn 45000 g/mol, Sigma-Aldrich, Milan, Italy) was received in pellet form and purified via 
dissolution in $\mathrm{CHCl}_{3}(15 \% \mathrm{wt} / \mathrm{vol})$ and reprecipitation in a large excess of cold $\mathrm{MeOH}$, in order to eliminate residual polymerization catalysts.

Dicalcium phosphate dihydrate (DCPD; $\mathrm{CaHPO}_{4} \cdot 2 \mathrm{H}_{2} \mathrm{O}$ ) powder (Sigma-Aldrich, Steinheim, Germany) and/or calcium silicate ( $\mathrm{CaSi}$ ) powders (Aalborg, Denmark), prepared by melt-quenching technique and milling procedures [8], and composed of dicalcium silicate, tricalcium silicate, tricalcium aluminate, and calcium sulfate, were added to PCL.

\subsection{Scaffolds preparation by TIPS}

The porous polymer scaffolds were prepared by TIPS starting from PCL solutions in DIOX (3.5\% wt/vol). CaSi and DCPD were added to the PCL solution in powder form in amounts $5 \%$ or $10 \%$ by weight with respect to PCL. Homogeneous dispersions were obtained by sonicating the mixtures for $3 \mathrm{~h}$ using the ultrasonic processor UP50H (Hielsher, 50 watts, $30 \mathrm{kHz}$ ), equipped with the sonotrode MS2 (made of titanium, tip diameter $2 \mathrm{~mm}$ ). After mixing, solutions were placed inside disposable aluminum dishes of 60 $\mathrm{mm}$ in diameter, and cooled at $-18^{\circ} \mathrm{C}$. After $18 \mathrm{~h}$, the frozen samples were extracted from the holders and fully immersed in $\mathrm{EtOH}$ bath precooled at $-18^{\circ} \mathrm{C}$, where they were kept for $72 \mathrm{~h}$, with solvent refresh every $24 \mathrm{~h}$. At the end of the extraction procedure, the porous scaffolds were taken out of the freezer, immersed in deionized water under ultrasounds treatment for at least 1 hour, then completely dried in forced-air circulating oven at $35^{\circ} \mathrm{C}[9,20]$ (Figure 1).

Six disks (diameter $60 \pm 1 \mathrm{~mm}$, thickness $10 \pm 0.1 \mathrm{~mm}$ ) per composition were prepared, to cover all characterization needs (Figure 2).

The prepared scaffolds were:

- PCL-10CaSi

- PCL-5CaSi-5DCPD

- PCL-10CaSi-10DCPD

- PCL (control)

\subsection{Bulk open porosity}

Bulk open porosity was measured according to the standard procedure UNI EN 1936 "Natural Stone Test Methods - Determination of real density and apparent density, and of total and open porosity". Briefly, dry and weighted specimens $\left(\mathrm{m}_{\mathrm{d}}\right)$ were put into an evacuation vessel and the pressure was lowered gradually to 20 mbar. The pressure was maintained for 2 hours to eliminate the air contained in the open pores of the specimens. Demineralized water at $20 \pm 5^{\circ} \mathrm{C}$ was slowly introduced into the vessel and the pressure was maintained at 20 mbar. After approximately 30 minutes and when all the specimens were completely immersed, the vessel was returned to atmospheric pressure and the specimens were left in water for 24 hours at atmospheric pressure. Then, each specimen was weighted in water and the mass in water was recorded as $\mathrm{m}_{\mathrm{h}}$. Each specimen was quickly wiped with a dampened cloth and the mass $\mathrm{m}_{\mathrm{s}}$ of the specimen saturated with water was determined. 
The open porosity $\mathrm{P}_{0}$ of the scaffold is expressed by the ratio (as a percentage) of the volume of open pores and the apparent volume of the specimen, by the equation $\mathrm{P}_{0}=\left(\mathrm{m}_{\mathrm{s}}-\mathrm{m}_{\mathrm{d}}\right) /\left(\mathrm{m}_{\mathrm{s}}-\mathrm{m}_{\mathrm{h}}\right) \times 100$.

The open porosity was determined in triplicate and expressed as mean \pm standard deviation.

Data collected on porosity were used to calculate an approximate value of the porous composite scaffolds from the equation $\mathrm{P}=\left(1-\rho_{\text {foam }} / \rho_{\text {matrix }}\right) \mathrm{X} 100$, assuming $\mathrm{PCL}$ density to be $1.14 \mathrm{~g} \mathrm{~cm}^{-3}$ and fillers density to be $2.5 \mathrm{~g} \mathrm{~cm}^{-3}$.

\subsection{Surface porosity by morphometric analysis on ESEM images}

ESEM images were analyzed through Image J program (National Institutes of Health, Bethesda, USA) to evaluate the scaffolds porosity, in terms of percentage [28]. Surface porosity was calculated as the ratio between the most black areas (micropores) and the total examined area. For each scaffold three measurements were performed in three different areas at $500 \times$ and $1000 \times$ magnification. For each magnification, the mean value was recorded. Surface porosity among the fresh scaffolds and $28 \mathrm{~d}$ aged scaffold was analyzed using Two-Way ANOVA followed by RM Student-Newman-Keuls test $(\mathrm{p}<0.05)$.

\subsection{Dynamic mechanical thermal properties}

Glass transition temperature (Tg), elastic modulus (E'), loss modulus (E") and loss factor (tanס) were determined through dynamic mechanical thermal analysis (DMTA) using a Q800 DMA equipment by TA Instruments (Delaware, USA). Cylindrical specimens (diameter $37 \pm 1 \mathrm{~mm}$, thickness $8 \pm 0.1 \mathrm{~mm}$ ) were tested in compression mode at a constant frequency of $1 \mathrm{~Hz}$, under strain control fixed at $1 \%$ while heated from -55 to $40{ }^{\circ} \mathrm{C}$ at a rate of $3{ }^{\circ} \mathrm{C} / \mathrm{min}$ under nitrogen gas flow. The specific storage modulus was calculated from the determined $\mathrm{E}^{\prime}$ values divided by porous scaffold density.

Melting and crystallization temperatures and the respective enthalpies of transition ( Tm, Tc, $\Delta \mathrm{Hm}, \Delta \mathrm{Hc}$ ) of the scaffolds were determined by means of a differential scanning calorimeter (DSC, Q10), fitted with a standard DSC cell, and equipped with a Discovery Refrigerated Cooling System (RCS90) (all TA Instruments, Delaware, USA). Samples of about $7 \mathrm{mg}$ were placed into aluminum pans and subjected to two heating cycles from $-50{ }^{\circ} \mathrm{C}$ to $+100{ }^{\circ} \mathrm{C}$ with cooling and heating rates of $10{ }^{\circ} \mathrm{C} / \mathrm{min}$. The DSC cell was purged with dry nitrogen at $50 \mathrm{~mL} / \mathrm{min}$. The system was calibrated both in temperature and enthalpy with Indium standard.

The real content of inorganic filler ( $\mathrm{CaSi}$ or $\mathrm{CaSi}+\mathrm{DCPD})$ present in the composite scaffolds was determined by thermogravimetric analysis (TGA, Q50, TA Instruments, Delaware, USA), as residual weight after polymer decomposition and complete volatilization. Analyses were performed in triplicate under dry nitrogen flow $(60 \mathrm{~mL} / \mathrm{min})$, on samples of about $20 \mathrm{mg}$, placed in platinum pans. Heating was performed from room temperature to $+600{ }^{\circ} \mathrm{C}$ at a rate of $10^{\circ} \mathrm{C} / \mathrm{min}$. Results are given as average value calculated over three samples.

All DMTA and DSC data were processed with Thermal Analysis software (TA Instruments, Delaware, USA). 


\subsection{Calcium release and alkalinizing activity ( $\mathrm{pH}$ of soaking water)}

The samples $(10 \pm 0.1 \mathrm{~mm}$ long $\times 10 \pm 0.1 \mathrm{~mm}$ high $\times 10 \pm 0.1 \mathrm{~mm}$ thick; $\mathrm{n}=6$ for each composition $)$ were immersed in $10 \mathrm{~mL}$ of deionized water inside polypropylene sealed containers and stored at $37^{\circ} \mathrm{C}$. The soaking water was collected and replaced at six time points ( 3 hours and 1, 3, 7, 14 and 28 days). The collected water was analyzed for $\mathrm{pH}$ and $\mathrm{Ca}^{2+}$ using a potentiometric method under magnetic stirring at room temperature $\left(24^{\circ} \mathrm{C}\right)$.

The $\mathrm{pH}$ was measured using a selective temperature-compensated electrode (Sen Tix Sur WTW, Weilheim, Germany) connected to a multi-parameter laboratory meter (inoLab 750 WTW, Weilheim, Germany) previously calibrated with standard solutions.

The amount of calcium ions was measured using a calcium probe (Calcium ion electrode, Eutech instruments Pte Ltd, Singapore) after addition of $0.200 \mathrm{~mL}(2 \%)$ of ionic strength adjuster ISA, $4 \mathrm{~mol} / \mathrm{L} \mathrm{KCl}$ (WTW, Weilheim, Germany).

Calcium release and $\mathrm{pH}$ data were analyzed using two-way ANOVA followed by RM Student-NewmanKeuls test $(p<0.05)$. Different letters represent statistically significant differences $(p<0.05)$ in the same line (capital letters) or in the same column (small letters).

\subsection{Calcium phosphate nucleation by ESEM-EDX, FT-Raman, micro-Raman and ATR/IR spectroscopy}

The apatite forming ability i.e. formation of a calcium phosphates (CaPs) on the scaffolds surface after soaking in Hank's balanced salt solution (HBSS, Lonza, Verviers, Belgium) was evaluated [8,9]. Each sample was placed in $20 \mathrm{~mL}$ of $\mathrm{HBSS}$ at $37^{\circ} \mathrm{C}$ for 28 days.

The fresh and aged scaffolds were analyzed by ESEM-EDX, FT-Raman, micro-Raman and ATR/IR spectroscopy.

An environmental scanning electron microscope (ESEM, Zeiss EVO 50; Carl Zeiss, Oberkochen, Germany) connected to a secondary electron detector for energy dispersive X-ray analysis (EDX; Oxford INCA 350 EDS, Abingdon, UK) using computer-controlled software (Inca Energy Version 18) was used. Specimens were placed directly onto the ESEM stub and examined in wet conditions without any previous preparation (the samples were not coated for this analysis) at low vacuum (100 Pascal). EDX microchemical analysis was carried out at random in areas of $\sim 50 \mu \mathrm{m} \times 50 \mu \mathrm{m}$ to evaluate the relative element content. Elemental microanalysis (weight \% and atomic \%) with ZAF correction method was performed in full frame to analyze entire areas.

Fourier Transform Raman (FT-Raman) spectroscopy was used to gain insights into the bulk of the samples, while the micro-Raman technique was utilized to analyze their surface. 
FT-Raman spectra were recorded on a Bruker MultiRam FT-Raman spectrometer equipped with a cooled Ge-diode detector. The excitation source was a $\mathrm{Nd}^{3+}$-YAG laser $(1064 \mathrm{~nm})$ in the backscattering $\left(180^{\circ}\right)$ configuration. The focused laser beam diameter was about $100 \mu \mathrm{m}$ and the spectral resolution $4 \mathrm{~cm}^{-1}$. Laser power at the sample was about $150 \mathrm{~mW}$. Three spectra on each sample were recorded and averaged.

Micro-Raman spectra were obtained using a Jasco NRS-2000C instrument in back-scattering conditions with $4 \mathrm{~cm}^{-1}$ spectral resolution, using the $532 \mathrm{~nm}$ Green Diode Pumped Solid State (DPSS) Laser Driver (RgBLase LLC, USA) with a power of ca. $20 \mathrm{~mW}$. A $160 \mathrm{~K}$ cooled digital CCD (Spec-10: 100B, Roper Scientific Inc.) was used as detector. Microscope objectives with $10 \times$ and $100 \times$ magnifications were utilized. The former was used to detect the doping agents in fresh PCL-5CaSi-5DCPD, i.e. the composite sample containing the lowest amount of each of them; in fact, under these conditions, the laser spot size, i.e. the excitation source was about $20 \mu \mathrm{m}$ and enable to obtain more representative spectra of these intrinsically inhomogeneous samples. The $100 \times$ magnification (with a laser spot size of about $1 \mu \mathrm{m}$ ) was used to analyze all the other samples. Each reported micro-Raman spectrum is an average of at least five measurements.

The $\mathrm{I}_{959(\mathrm{Ap}+\mathrm{PCL})} / \mathrm{I}_{1443(\mathrm{PCL})}$ and $\mathrm{I}_{959(\mathrm{Ap}+\mathrm{PCL})} / \mathrm{I}_{1306(\mathrm{PCL})}$ Raman ratios (where $\mathrm{I}_{959(\mathrm{Ap}+\mathrm{PCL})}, \mathrm{I}_{1443(\mathrm{PCL})}$ and $\mathrm{I}_{1306(\mathrm{PCL})}$ were the intensities of the bands at 959, 1443 and $1306 \mathrm{~cm}^{-1}$, respectively) were used to assess the relative thickness of the apatite phase enucleated on the different scaffolds. In fact, the band at $959 \mathrm{~cm}^{-1}$ is assignable to apatite [22] besides PCL [23], while PCL bands at 1443 and $1306 \mathrm{~cm}^{-1}$ were used as internal standards, due to their assignments to both amorphous and crystalline phases of the polymer [23] (and thus their intensity does not depend on possible changes in polymer crystallinity induced by ageing). Although these ratios do not represent a measurement of the absolute thickness of the apatite phase, they allow a comparative evaluation between samples. In fact, at increasing apatite thickness, the contribution of the PCL bands to the Raman spectrum of the aged scaffolds progressively decreases, determining a progressive increase in the $\mathrm{I}_{959(\mathrm{Ap}+\mathrm{PCL})} / \mathrm{I}_{1443(\mathrm{PCL})}$ and $\mathrm{I}_{959(\mathrm{Ap}+\mathrm{PCL})} / \mathrm{I}_{1306(\mathrm{PCL})}$ Raman ratios.

Raman spectroscopy is a powerful technique for characterizing chain conformation and crystallinity in semicrystalline polymers; in contrast to diffraction methods, it can also test short-range ordering. Several studies have used Raman spectroscopy to quantitatively determine PCL crystallinity [Olga Hartman, Chu Zhang, Elizabeth L. Adams, Mary C. Farach-Carson, Nicholas J. Petrelli, Bruce D. Chase, John F. Rabolt. Biofunctionalization of electrospun PCL-based scaffolds with perlecan domain IV peptide to create a 3-D 
pharmacokinetic cancer model. Biomaterials 31 (2010) 5700-5718. Anna Baranowska-Korczyc, Alicja Warowicka, Małgorzata Jasiurkowska-Delaporte, Bartosz Grzeskowiak, Marcin Jarek, Barbara M. Maciejewska, Justyna Jurga-Stopa, Stefan Jurga. Antimicrobial electrospun poly(e-caprolactone) scaffolds for gingival fibroblast growth. RSC Adv., 2016, 6, 19647-19656. Yuhui Yang, Min Chen, Huanbin Li, Hanying Li, The degree of crystallinity exhibiting a spatial distribution in polymer films European Polymer Journal 107 (2018) 303-307. A. Wesełucha-Birczyńska, M. Świętek, E. Sołtysiak, P. Galiński, Ł. Płachta, K. Piekara, M. Błażewicz, Raman spectroscopy and the material study of nanocomposite membranes from poly(E-caprolactone) with biocompatibility testing in osteoblast-like cells. Analyst, 2015, 140, 2311-20. Anthony P. Kotula, Chad R. Snyder, Kalman B. Migler, Determining conformational order and crystallinity in polycaprolactone via Raman spectroscopy. Polymer 117 (2017) 1-10.]. In agreement with previous investigations [24-27, A. Wesełucha-Birczyńska, M. Świętek, E. Sołtysiak, P. Galiński, Ł. Płachta, K. Piekara, M. Błażewicz, Raman spectroscopy and the material study of nanocomposite membranes from poly( $\varepsilon$-caprolactone) with biocompatibility testing in osteoblast-like cells. Analyst, 2015, 140, 2311-20.], the PCL crystallinity was relatively evaluated through the Raman $\mathrm{I}_{1419(\mathrm{PCL})} / \mathrm{I}_{1443(\mathrm{PCL} C+\mathrm{A})}$ and $\mathrm{I}_{1285(\mathrm{PCL})} / \mathrm{I}_{1306(\mathrm{PCL}}$ C+A) intensity ratios, where $\mathrm{I}_{1419(\mathrm{PCL})}$ and $\mathrm{I}_{1285(\mathrm{PCL})}$ were the intensity of the bands at 1419 and $1285 \mathrm{~cm}^{-1}$, assignable to the crystalline phase [23], while $\mathrm{I}_{1443(\mathrm{PCL} C+\mathrm{A})}$ and $\mathrm{I}_{1306(\mathrm{PCL} C+\mathrm{A})}$ were the intensities of the already mentioned internal standard bands at 1443 and $1306 \mathrm{~cm}^{-1}$. All the ratios were calculated as peak heights from the single spectra recorded on each sample. Average values are reported and discussed. Although these ratios do not represent a direct measurement of the PCL crystallinity, they allow to follow its trend with time. To further support the results obtained through these ratios, the PCL C=O stretching region $\left(1750-1710 \mathrm{~cm}^{-1}\right)$ has been analyzed by band fitting according to previous studies [Olga Hartman, Chu Zhang, Elizabeth L. Adams, Mary C. Farach-Carson, Nicholas J. Petrelli, Bruce D. Chase, John F. Rabolt. Biofunctionalization of electrospun PCL-based scaffolds with perlecan domain IV peptide to create a 3-D pharmacokinetic cancer model. Biomaterials 31 (2010) 5700-5718. Anna Baranowska-Korczyc, Alicja Warowicka, Małgorzata Jasiurkowska-Delaporte, Bartosz Grzeskowiak, Marcin Jarek, Barbara M. Maciejewska, Justyna JurgaStopa, Stefan Jurga. Antimicrobial electrospun poly(e-caprolactone) scaffolds for gingival fibroblast growth. RSC Adv., 2016, 6, 19647-19656. Yuhui Yang, Min Chen, Huanbin Li, Hanying Li, The degree of crystallinity exhibiting a spatial distribution in polymer films. European Polymer Journal 107 (2018) 303- 
307. A. Wesełucha-Birczyńska, M. Świętek, E. Sołtysiak, P. Galiński, Ł. Płachta, K. Piekara, M. Błażewicz, Raman spectroscopy and the material study of nanocomposite membranes from poly( $\varepsilon$-caprolactone) with biocompatibility testing in osteoblast-like cells. Analyst, 2015, 140, 2311-20.]. The curve-fitting analysis was performed using the OPUS/IR version 2.0 program, which uses the Levenberg-Marquardt algorithm. After baseline correction, the band fitting procedure allowed to decompose the $\mathrm{C}=\mathrm{O}$ stretching spectral profile into its three components at about 1736,1728 and $1724 \mathrm{~cm}^{-1}$, assigned to a random coil PCL chain conformation ("amorphous 1"), an otherwise structureless coil with $\mathrm{C}=\mathrm{O}$ bonds on neighboring chains oriented antiparallel to each other due to dipole-dipole interactions ("amorphous 2") and ordered chains packed into the crystal lattice (“crystalline"), respectively [Anthony P. Kotula, Chad R. Snyder, Kalman B. Migler, Determining conformational order and crystallinity in polycaprolactone via Raman spectroscopy. Polymer 117 (2017) 1-10.]. The Raman component profiles were described as a linear combination of Lorentzian and Gaussian functions. The content of each structure was calculated from the area of the individually assigned bands and expressed as fraction of the total area.

\subsection{Direct-contact cytotoxicity test}

\subsubsection{Cell culture}

Cell viability and proliferation experiments were carried out using the mouse embryo fibroblasts balb/3T3 clone A31 cell line (CCL-163). Cells were purchased from American Type Culture Collection (ATCC) and propagated using Dulbecco's Modified Eagle Medium (DMEM), supplemented with $4 \mathrm{mM}$ of L-glutamine, $1 \%$ of penicillin: streptomycin solution $(10,000 \mathrm{U} / \mathrm{ml}: 10 \mathrm{mg} / \mathrm{ml}), 10 \%$ of calf serum and antimycotic (complete DMEM).

The scaffolds were mounted in CellCrownTM24 disposable inserts (Scaffdex, Tampere, Finland), placed in 24-wells plate and sterilized with an Ethanol:H2O (70:30 v/v) solution for 30 minutes. Afterwards, samples were extensively washed with Dulbecco's Phosphate Buffer Saline (DPBS) containing 1\% penicillin: streptomycin solution and pre-incubated for additional 3 hours with complete DMEM before cell seeding.

\subsubsection{Cell viability and proliferation by mitochondrial activity test}

Samples were seeded with mouse embryo fibroblast balb/3T3 clone A31 cells (passage 73) by directly adding on to the scaffold surface $500 \mathrm{ul}$ of DMEM containing $1 \times 10^{4}$ cells $/$ per well and incubated at $37^{\circ} \mathrm{C}$ in a $5 \% \mathrm{CO}_{2}$ enriched atmosphere.

Cell tests were performed at days 7 and 14 after seeding. Cell proliferation was investigated by mean of WST-1 tetrazolium salt reagent (Roche Applied Science, Indianapolis, IN, USA). Briefly, cells were incubated for 4 hours with WST-1 reagent diluted $1: 10$, at $37^{\circ} \mathrm{C}$ and $5 \% \mathrm{CO}_{2}$. Measurements of formazan 
dye absorbance were carried out with a microplate reader (Biorad, Milan, Italy) at $450 \mathrm{~nm}$, using $655 \mathrm{~nm}$ as reference wavelength. Cells at day 7 of culture cultured on tissue culture polystyrene (TCPS) were used as growth control.

The tests were performed in triplicate on the whole scaffold/cell construct and the data are reported as mean \pm standard deviation. Statistical differences were analyzed using one-way analysis of variance (ANOVA) and a $\mathrm{p}$ value $<0.05$ was considered significant.

\subsubsection{Cell morphological and cytoskeleton organization by Confocal Laser Scanning Microscopy (CLSM)}

Cells morphology cultured on the experimental PCL-based scaffolds was investigated by CLSM at day 14 after seeding. Cells were fixed with 3.8\% paraformaldehyde for 1 hour in Phosphate Buffer Saline 0.01 M (PBS 1X) at room temperature and permeabilized with a PBS $1 \mathrm{X} /$ Triton X-100 solution $(0.2 \%)$ for $10 \mathrm{~min}$. After blocking with 1\% (w/v) bovine serum albumin (BSA) in PBS 1X for $30 \mathrm{~min}$, cells were incubated with phalloidin-Alexa Fluor 488 at room temperature in the dark for 1 hour and then with 4'-6- diamidino-2phenylindole (DAPI) solution for 30 minutes, to stain cells nuclei and F-Actin. Following each dyeing incubation, samples were extensively washed with PBS $1 \mathrm{X}$ and finally stored at $4{ }^{\circ} \mathrm{C}$ in the dark until observation by confocal laser scanning microscopy was performed. A Nikon Eclipse TE2000 inverted microscope equipped with EZ-C1 confocal laser (Nikon, Japan) with $10 \times$ and $20 \times$ objectives was used to analyze the samples. A 405nm laser diode (405 nm emission) and an Argon ion laser (488 nm emission) were used to excite DAPI and Alexa-Fluor 488 fluorophores, respectively. Images were captured with Nikon EZ-C1 software with identical settings for each sample.

\section{Results}

\subsection{Bulk open porosity, thermal and mechanical properties}

TIPS procedure allowed to obtain all samples with bulk open porosity of about $95 \%$; porosity values and weight contents of inorganic fillers as determined through TGA for all the composite scaffolds, are reported in Table 1. PCL melting temperature observed in the second heating scan and crystallization temperature observed during the cooling scan and their respective enthalpies of transition determined by DSC are reported in Table 2, along with the percentage of crystallinity. The percentage of crystallinity was calculated as shown in the following equation $\chi c=\left[\left(\Delta \mathrm{H}_{\mathrm{M}}-\Delta \mathrm{H}_{\mathrm{C}}\right) / \Delta \mathrm{H}^{0}{ }_{\mathrm{M}}\right] \mathrm{x} 100$.

where $\chi c$ is percentage of crystallinity, $\Delta \mathrm{H}_{\mathrm{M}}$ and $\Delta \mathrm{H}_{\mathrm{C}}$ are the enthalpy of melting during the first heating scan and crystallization during cooling, respectively, and $\Delta \mathrm{H}_{\mathrm{M}}^{0}=136 \mathrm{~J} / \mathrm{g}$ (melting enthalpy for $100 \%$ of crystalline PCL) [31].

Table 3 collects dynamic mechanical properties (glass transition temperature-Tg, elastic modulus-E', loss modulus-E", loss factor-tanס) determined by DMTA [32].

\subsection{Calcium release and alkalizing activity $(\mathrm{pH})$}

Ion release values evaluated at different time endpoints are showed in Table 4. 
Pure PCL scaffolds showed no/negligible ability to release calcium $(4.77 \pm 2.20 \mathrm{ppm})$. The mineral-doped scaffolds showed a moderate ability to release Calcium ions. Cumulative release of calcium ions (mean $\pm \mathrm{SD}$, expressed in ppm) ranged from $67.91 \pm 27.34$ for PCL-5CaSi-5DCPD to $101.78 \pm 15.83$ of PCL-10CaSi10DCPD.

Calcium release decreased during the testing time, but remained markedly higher than PCL for all 28 days $(\mathrm{p}<0.05)$, demonstrating a potential long-term activity for all the mineral-doped samples (except for PCL5CaSi-5DCPD, which showed a non-linear trend).

PCL-10CaSi-10DCPD showed the highest calcium release values from 3 hours to 7 days, differences were statistically significant compared to the other samples from 3 hours to 3 days $(\mathrm{p}<0.05$ ).

PCL-10CaSi and PCL5CaSi-5DCPD showed the highest initial calcium release values.

Alkalinizing activity showed a marked increase in the first three hours (Table 5), ranging from $9.29 \pm 0.50$ to $8.92 \pm 0.45$ for the mineral-doped scaffolds.

The $\mathrm{pH}$ increase remained relevant until 1 day for PCL-10CaSi-10DCPD and PCL-5CaSi-5DCPD. In particular, PCL-10CaSi-10DCPD showed the highest alkalinizing ability at 3 hours and 1 day (mean values were 9.29 and 9.11), statistically different from all the mineral doped scaffolds $(\mathrm{p}<0.001)$. Then, after 3 days, $\mathrm{pH}$ decreased and remained not statistically different from both pure PCL and deionized water ( $\mathrm{p}>0.05)$.

\subsection{ESEM and Surface Porosity, EDX, Raman analyses}

\subsubsection{PCL scaffolds}

ESEM analysis at 500 and $1000 \times$ magnifications (Figures 3a and b) revealed an irregular porous structure on the entire surface with large pores, ranging from 20 to $200 \mu \mathrm{m}$. The shape of these pores were mostly elliptic or circular.

The mean surface porosity, evaluated on three random areas at $500 \times$ and $1000 \times$ magnification, was $51.58 \%$ (range 49.25-54.16\%) and 52.22\% (range 47.18-59.11\%), respectively.

EDX on spectra on one random area, as well as on the entire area (Figures 3c and d) showed PCL constitutional peaks, namely Carbon (C) and Oxygen (O).

The FT-Raman and micro-Raman average spectra of the fresh PCL scaffold showed the bands characteristic of both crystalline and amorphous phases [23], as indicated in the Figures $4 \mathbf{a}$ and $\mathbf{b}$; this result reveals the semi-crystalline character of the polymer.

After 28 days soaking in HBSS, ESEM at 500x and 1000x magnification (Figures 3e and f) showed a uniform rough surface with small circular pores, ranging from 10 to $20 \mu \mathrm{m}$ (smaller than that of fresh samples). Mean surface porosity, calculated on 3 random areas at at $500 \times$ and $1000 \times$ magnification was $48.67 \%$ (range $45.78-51.17 \%$ ) and $49.89 \%$ (46.54-55.19\%). No statistically significant differences were present between porosity of fresh and $28 \mathrm{~d}$ aged samples $(\mathrm{p}=0.233)$

Punctual EDX spectra, as well as those of the entire area, (Figures $\mathbf{3 g}$ and $\mathbf{h}$ ) revealed scaffold constitutional peaks $(\mathrm{C}, \mathrm{O})$ and small amounts of sodium $(\mathrm{Na})$ and Chlorine $(\mathrm{Cl})$ (attributable to HBSS medium). 
After ageing in HBSS, micro-Raman spectroscopy showed an increase in the relative intensity of the band at $959 \mathrm{~cm}^{-1}$ (Figure 4b); it must be observed that this band is present also in the spectrum of the PCL polymer [23] and its strengthening upon HBSS is ascribable to the superposition of the $\mathrm{PO}_{4}{ }^{3-}$ symmetric stretching mode of an apatite phase [22] deposited on the surface of the scaffold. The trend of the Raman $\mathrm{I}_{959(\mathrm{Ap}+\mathrm{PCL})} / \mathrm{I}_{1443(\mathrm{PCL})}$ and $\mathrm{I}_{959(\mathrm{Ap}+\mathrm{PCL})} / \mathrm{I}_{1306(\mathrm{PCL})}$ intensity ratios confirmed apatite deposition (Figure 4c); in fact, both these ratios increased upon ageing in HBSS, although the high standard deviation associated to the measurements suggest that the deposit was not uniformly distributed to the scaffold surface. Moreover, it must be observed that the FT-Raman technique did not detect any strengthening of the $959 \mathrm{~cm}^{-1}$ (Figure 4b); this result showed that apatite deposition prevalently involved the sample surface (to which the micro-Raman technique is sensitive) rather than the bulk (of which the FT-Raman spectrum is representative). Nevertheless, it must be stressed that the micro-Raman spectrum of the HBSS-aged scaffold still showed the bands of the polymer, suggesting that the thickness of the apatite deposit was not enough to mask the scaffold underneath.

With regards to the polymeric component, both FT-Raman and micro-Raman average spectra (Figure 4a and b) showed that upon ageing in HBSS, the bands characteristic of the crystalline phase decreased in intensity, while those assignable to the amorphous phase strengthened. To follow the trend of PCL crystallinity, the Raman $\mathrm{I}_{1419(\mathrm{PCL})} / \mathrm{I}_{1443(\mathrm{PCL} C+\mathrm{A})}$ and $\mathrm{I}_{1285(\mathrm{PCL})} / \mathrm{I}_{1306(\mathrm{PCL} C+\mathrm{A})}$ intensity ratios were calculated from both FT-Raman and micro-Raman spectra and their trend is reported in Figure S1, Supplementary Material; as can be seen from the histograms, both ratios generally decreased upon ageing, suggesting a certain increase in the amorphous character of the scaffold upon ageing. To further support this trend, the $\mathrm{C}=\mathrm{O}$ stretching band has been analyzed by curve fitting, and Figure S2, Supplementary Material reports as an example the FT-Raman spectra of fresh and HBSS-aged scaffolds fitted into their "crystalline", "amorphous 1" and "amorphous 2" components. The percentages of each structure obtained by this procedure are reported in Figure S3, Supplementary Material; as can be easily seen, both FT-Raman and micro-Raman fitting data confirmed a certain decrease in PCL crystallinity.

\subsubsection{PCL-10CaSi scaffolds}

ESEM micro-analysis at 500 $\times$ and $1000 \times$ magnifications (Figures 5a and b) was carried out on the fresh sample surface, revealing a honeycomb-like regular structure. Pores were mostly circular, their diameter ranged from 15 to $30 \mu \mathrm{m}$. Small dense granules were uniformly spread on all the surface.

The mean surface porosity, evaluated on three random areas at $500 \times$ and $1000 \times$ magnification, was $55.16 \%$ (range 52.32-60.21\%) and 56.43\% (range 54.15-58.71\%), respectively.

EDX on fresh samples (Figure 5c) revealed, besides the constitutional peaks $(\mathrm{C}, \mathrm{O})$, also presence of $\mathrm{Ca}$ and traces of Si (from CaSi powder). Punctual EDX (Figure 5d) on one granule revealed the presence of $\mathrm{Ca}$ and $\mathrm{Si}$, but also traces of Aluminium (Al) and Sulphur (S). Atomic Ca/Si ratio was 2.98.

The FT-Raman average spectrum of the fresh PCL-10CaSi scaffold was of bad quality because of the high fluorescence background [29] due to the calcium silicate cement (Figure 6a); most of the bands of PCL were observed although with low intensity. For this reason, the $\mathrm{I}_{1419(\mathrm{PCL})} / \mathrm{I}_{1443(\mathrm{PCL} \mathrm{C}+\mathrm{A})}$ and $\mathrm{I}_{1285(\mathrm{PCL} C)} / \mathrm{I}_{1306(\mathrm{PCL}}$ 
$\mathrm{C}+\mathrm{A})$ intensity ratios appeared unreliable and thus were not calculated. The PCL bands below $1000 \mathrm{~cm}^{-1}$ were hardly detectable due to the strong fluorescence bands at about 805 and $730 \mathrm{~cm}^{-1}$ assignable to belite [29]. Therefore, it was not possible calculate the $\mathrm{I}_{959} / \mathrm{I}_{1443}$ and $\mathrm{I}_{959} / \mathrm{I}_{1306}$ ratios.

The micro-Raman average spectrum of the same scaffold (Figure 6b) showed the bands of both PCL and CaSi component (in particular, alite and belite phases [29,30]. The above mentioned marker ratios of PCL crystallinity, i.e. $\mathrm{I}_{1419(\mathrm{PCL})} / \mathrm{I}_{1443(\mathrm{PCL} \mathrm{C}+\mathrm{A})}$ and $\mathrm{I}_{1285(\mathrm{PCL})} / \mathrm{I}_{1306(\mathrm{PCL} C+\mathrm{A})}$, were not significantly different with respect to pure PCL scaffolds.

After 28 days of immersion in HBSS, ESEM showed (Figure 5e) a similar structure with the deposition of a small mineral layer on the scaffold surface. This layer was not uniformly distributed on all the scaffold surface.

The mean surface porosity, evaluated on three random areas at 500× and $1000 \times$ magnification, was $57.35 \%$ (range 56.58-57.78\%) and 56.96\% (range 51.66-63.14\%), respectively. No statistically significant differences were present between porosity of fresh samples and that of $28 \mathrm{~d}$ aged samples $(\mathrm{p}=0.555)$

ESEM images of one area at high magnification (Figure 5f) revealed irregularities on the honeycomb-like structure with the presence of aggregated mineral deposits.

EDX on the entire area (Figure 5g), as well as punctual EDX (Figure 5h) revealed the constitutional elements $(\mathrm{C}, \mathrm{O})$, the appearance of $\mathrm{Na}, \mathrm{Cl}$ and $\mathrm{P}$, and a moderate increase of $\mathrm{Ca}$. Traces of $\mathrm{Si}$ and $\mathrm{Al}$ were also detected.

Atomic $\mathrm{Ca} / \mathrm{P}$ ratio calculated on the entire area was 1.67 , while on the punctual spectrum was 2.35 .

After ageing in HBSS, the FT-Raman average spectrum of PCL-10CaSi (Figure 6a) showed a marked decrease in the fluorescence bands of belite and the spectrum background significantly improved. Some PCL bands that were not detected in the spectrum of the fresh sample became observable. Both the FT-Raman and micro-Raman average spectra of the aged scaffold showed a band at about $1085 \mathrm{~cm}^{-1}$ assignable to calcite. No significant changes in the $\mathrm{I}_{959(\mathrm{Ap}+\mathrm{PCL})} / \mathrm{I}_{1443(\mathrm{PCL})}$ and $\mathrm{I}_{959(\mathrm{Ap}+\mathrm{PCL})} / \mathrm{I}_{1306(\mathrm{PCL})}$ intensity ratios were observed in the micro-Raman spectra; thus, no significant $\mathrm{CaP}$ deposition was detected.

\subsubsection{PCL-5CaSi-5DCPD scaffolds}

ESEM images at 500× magnification on fresh sample (Figures 7a) showed an irregular structure, less porous than the previous investigated samples. Large but sparse irregular pores, ranging from 30 to $200 \mu \mathrm{m}$, were present on the surface. Some granules can be appreciated at higher magnification (1000x) (Figures 7b).

The mean surface porosity, evaluated on three random areas at $500 \times$ and $1000 \times$ magnification, was $38.27 \%$ (range 35.59-39.62\%) and 40.42\% (range 33.69-44.28\%), respectively.

EDX on the entire area (Figure 7c) revealed constitutional elements $(\mathrm{C}, \mathrm{O})$ and traces of $\mathrm{Ca}$ and P. EDX on one granule (Figure 7d) revealed the presence of $\mathrm{Ca}, \mathrm{Si}, \mathrm{Al}$ (from $\mathrm{CaSi}$ ), $\mathrm{C}$ and $\mathrm{O} . \mathrm{Ca} / \mathrm{Si}$ ratio was 3.12. The FT-Raman average spectrum of the fresh PCL-5CaSi-5DCPD was similar to that of fresh PCL-10CaSi, although of a better quality, in agreement with the lower CaSi content of the former (Figure 8a). The 
average micro-Raman spectrum of fresh PCL-5CaSi-5DCPD recorded at a $100 \times$ magnification did not show the bands of $\mathrm{CaSi}$ and DCPD doping agents (Figure 8b). However, these components were detected by using a 10× magnification (Figure S4, Supplementary Material).

As observed also for the PCL-10CaSi scaffold, the spectral features assignable to the PCL polymer did not show significant changes in relative intensity with respect to the pure PCL scaffold (compare Figures $\mathbf{4}$ and 8), and no significant changes in the $\mathrm{I}_{1419(\mathrm{PCL})} / \mathrm{I}_{1443(\mathrm{PCL} C+\mathrm{A})}$ and $\mathrm{I}_{1285(\mathrm{PCL})} / \mathrm{I}_{1306(\mathrm{PCL} C+\mathrm{A})}$ intensity ratios were observed.

After 28 days of immersion in HBSS, ESEM showed (Figure 7e) a honeycomb-like structure, with more regular and numerous circular pores, their diameter ranged from 20 to $50 \mu \mathrm{m}$. At higher magnification (Figure 7f) a heterogeneous, yet constant, mineral layer can be observed on the scaffold surface also present into some pores.

The mean surface porosity, evaluated on three random areas at $500 \times$ and $1000 \times$ magnifications, was $51.13 \%$ (range 48.11-53.06\%) and 50.98\% (range 48.70-52.50\%), respectively. Statistically significant differences were present between porosity of fresh and $28 \mathrm{~d}$ aged samples $(\mathrm{p}<0.001)$

EDX on the entire area (Figure $7 \mathbf{g}$ ) of the $28 \mathrm{~d}$ aged sample revealed, besides the constitutional peaks $(\mathrm{C}, \mathrm{O})$ and the elements from the HBSS medium $(\mathrm{Na}, \mathrm{Cl}$ and Potassium $(\mathrm{K}))$, the increase of $\mathrm{Ca}$, the appearance of P. Punctual EDX on one mineral deposit (Figure 7h) revealed the appearance of the same elements from the medium ( $\mathrm{Na}, \mathrm{Cl}, \mathrm{K}$ and traces of Magnesium $(\mathrm{Mg})$ ), constitutional elements $(\mathrm{C}, \mathrm{O})$, the marked decrease of $\mathrm{Si}$ and the marked appearance of $\mathrm{P}$. Atomic $\mathrm{Ca} / \mathrm{P}$ ratio was 1.68 on the punctual spectrum, while on the entire area was 1.53 .

Upon ageing in HBSS, the FT-Raman spectrum of the PCL-5CaSi-5DCPD scaffold improved (Figure 8a), suggesting the formation of a deposit masking the fluorescence of the CaSi component underneath. The average micro-Raman spectrum recorded on this aged scaffold (Figure 8b) showed a certain increase in the

relative intensity of the $959 \mathrm{~cm}^{-1}$ band and thus in the $\mathrm{I}_{959(\mathrm{Ap}+\mathrm{PCL})} / \mathrm{I}_{1443(\mathrm{PCL})}$ and $\mathrm{I}_{959(\mathrm{Ap}+\mathrm{PCL})} / \mathrm{I}_{1306(\mathrm{PCL})}$ intensity ratios (Figure 9c). These results suggest that the deposit was mainly composed of apatite.

No significant changes in the $\mathrm{I}_{1419(\mathrm{PCL})} / \mathrm{I}_{1443(\mathrm{PCL}+\mathrm{A})}$ and $\mathrm{I}_{1285(\mathrm{PCL})} / \mathrm{I}_{1306(\mathrm{PCL}+\mathrm{A})}$ intensity ratios were observed upon ageing.

\subsubsection{PCL-10CaSi-10DCPD scaffolds}

ESEM on fresh samples at $500 \times$ magnification (Figure 9a) showed a porous honeycomb-like regular structure with well distributed mineral granules. At higher magnification (Figure 9b) small circular pores were observed; their diameter ranged from 15 to $30 \mu \mathrm{m}$.

The mean surface porosity, evaluated on three random areas at $500 \times$ and $1000 \times$ magnifications, was $41.42 \%$ (range 35.61-45.99\%) and 41.65\% (range 37.97-45.93\%), respectively.

EDX on the entire area (Figure 9c), as well as on one granule (Figure 9d), showed C,O (attributable to PCL structure), $\mathrm{Ca}, \mathrm{Si}, \mathrm{P}$ and $\mathrm{Al}$ (from $\mathrm{CaSi}$ and DCPD granules). $\mathrm{Ca} / \mathrm{Si}$ ratio calculated on one granule was 3.75. 
The FT-Raman average spectrum of the fresh PCL-10CaSi-10DCPD scaffold (Figure 10a) was similar to that of PCL-10CaSi (Figure 6a), as expectable on the basis of the similar CaSi contents of these samples.

The micro-Raman average spectrum of fresh PCL-10CaSi-10DCPD (Figure 10b) did not display the bands of the DCPD and CaSi components, which were detected in a single spectrum (Figure S5, Supplementary Material). The presence of the doping agents was found not to alter the $\mathrm{I}_{1419 \text { (PCL C) }} / \mathrm{I}_{1443(\mathrm{PCL} C+\mathrm{A})}$ and $\mathrm{I}_{1285(\mathrm{PCL}}$ C) $/ \mathrm{I}_{1306(\mathrm{PCL} C+\mathrm{A})}$ intensity ratios if compared with the pure PCL scaffold.

After 28d immersion in HBSS, the surface appeared markedly different. ESEM showed (Figures 9e and f) a mineral layer partially covering a more porous structure. Pores ranged from 20 to $50 \mu \mathrm{m}$, a great number of them were obtruded by the mineral deposits.

The mean surface porosity, evaluated on three random areas at 500× and $1000 \times$ magnification, was $42.01 \%$ (range 38.14-44.17\%) and 36.89\% (range 35.94-37.51\%), respectively. No statistically significant differences were present between porosity of fresh and $28 \mathrm{~d}$ aged samples $(\mathrm{p}=0.924)$.

EDX on the entire area revealed (Figure 9g), besides the elements attributable to the scaffold constitution $(\mathrm{C}, \mathrm{O})$ and the HBSS, the marked increase of P and the decrease of Si. Ca slightly decreased. Interestingly, punctual EDX on the deposit (Figures 9h) revealed the marked increase of P and the disappearance of Si. Atomic $\mathrm{Ca} / \mathrm{P}$ ratio, calculated on the entire area, was 1.78 , while on punctual spectrum was 2.68 .

Upon ageing in HBSS, the FT-Raman average spectrum significantly improved and the fluorescence bands of belite component were observable only with a very low intensity (Figure 10a). In the micro-Raman average spectrum significant strengthening of the $959 \mathrm{~cm}^{-1}$ band was observed (Figure 10b) and correspondingly the $\mathrm{I}_{959(\mathrm{Ap}+\mathrm{PCL})} / \mathrm{I}_{1443(\mathrm{PCL})}$ and $\mathrm{I}_{959(\mathrm{Ap}+\mathrm{PCL})} / \mathrm{I}_{1306(\mathrm{PCL})}$ intensity ratios noticeably increased (Figure 10c). On the contrary, the $I_{1419(\mathrm{PCL})} / \mathrm{I}_{1443(\mathrm{PCL}+\mathrm{A})}$ and $\mathrm{I}_{1285(\mathrm{PCL})} / \mathrm{I}_{1306(\mathrm{PCL} C+\mathrm{A})}$ intensity ratios did not change upon ageing. To gain more insights into the formed deposit, Figure S6, Supplementary Material shows a single micro-Raman spectrum (i.e. recorded on a single point) of PCL10CaSi-10DCPD aged for 28d in HBSS; the micro-Raman spectrum of a B-type carbonated apatite has been reported for reference as well as that of the fresh scaffold. As can be easily seen, in this single spectrum, the $959 \mathrm{~cm}^{-1}$ band appears much stronger than in the average one. Figure Figure S7, Supplementary Material reports the results of the $\mathrm{C}=\mathrm{O}$ band fitting analysis performed on the micro-Raman spectra of the fresh and HBSS-aged PCL10CaSi10DCPD scaffolds (average and single spectra). As can be seen from these data, upon ageing, the PCL crystallinity did not significantly change. Therefore, the increase in the relative intensity of the band at 1067 $\mathrm{cm}^{-1}$ (Figure 10b and Figure S6, Supplementary Material), which has a contribution from crystalline PCL, may be interpreted as only due to the contribution of the $\mathrm{CO}_{3}{ }^{2-}$ mode stretching mode of a B-type carbonated apatite [22]. Other bands of this phase (assignable to $\mathrm{PO}_{4}{ }^{3-}$ bending modes) were detected around 600 and $400 \mathrm{~cm}^{-1}$ in both average and single spectra (Figure 10b and Figure S6, Supplementary Material). In the single spectrum, these bands appeared evidently stronger, due to the higher thickness of the deposit in the position where it was recorded. 


\subsection{Cell response}

The in vitro biocompatibility of the investigated PCL-based composite scaffolds was assessed quantitatively by measuring cell viability and proliferation, employing WST-1 cell proliferation reagent. The test is based on the mitochondrial enzymatic conversion of the tetrazolium salt WST-1 into soluble formazan, occurring only in metabolically active cells. The amount of formazan dye directly correlates with the number of viable cells present in the sample. Balb/3T3 clone A31 cell proliferation was monitored at days 7 and 14 after seeding (Figure 11) .

Investigations of cell morphology and cytoskeleton organization of Balb/3T3 cultured on the composites scaffolds were carried out by CLSM analysis. Cells were stained for F-actin and nuclei with phalloidinAlexa Fluor 488 and DAPI respectively. After 14 days of culture microscopic observations confirmed the quantitative data and revealed the presence of Balb/3T3 cells on all the investigated samples. The occurring of a good degree of cell colonization of the developed scaffolds is confirmed by the visualization and distribution of cell nuclei, stained with DAPI (Figure 12).

\section{Discussion}

The production of porous bioactive and biodegradable scaffolds is important in a great number of medical fields, such as oncological and orthopaedic surgery, maxillo-facial and oral surgery, periodontal and endodontic surgery.

In the present study biocompatible, bioactive (apatite forming) and biointeractive (able to release biologically relevant ions) mineral-doped PCL-based porous scaffolds were fabricated.

Following previously investigations on PLA matrices [9], CaSi and DCDP were included into PCL matrix to improve the polymer properties for tissue engineering, by reducing its hydrophobicity and enhancing its biological activity, to promote cells adhesion, growth and proliferation.

Previously, hybrid PCL-polyglycolic acid solution was used to produce biodegradable scaffolds by a 3D mould for human tooth-ligament in dental applications [33]. Then, PCL composites containing biphasic calcium phosphate $(80: 20 \mathrm{wt} \%)$ prepared by hot melt extrusion $\left(100^{\circ} \mathrm{C}\right)$ for $3 \mathrm{D}$ printing were able to support the differentiation of human dental pulp stem cells into osteogenic lineage in calvarial defects [34]. PCL composites doped with $10-50 \mathrm{wt} \%$ of $\beta$-tricalcium phosphate produced by a foaming agent and heating at $90^{\circ} \mathrm{C}$ demonstrated to promote proliferation of human bone marrow mesenchymal stem cells also supporting the differentiation to reparative hard tissue [35].

Recently, PCL composites doped with $10-50 \mathrm{wt} \%$ of calcium silicate-based powders stirred at high temperatures $\left(200^{\circ} \mathrm{C}\right)$ were used to fabricate scaffolds for bone tissue engineering applications through $3 \mathrm{D}$ printing [41]. 
An opposite approach has been followed in two recent studies where commercial HCSC powders (ProRoot MTA or Biodentine) were added with PCL (60:40 wt\%) used as linker to produce scaffolds for pulp regeneration by $3 \mathrm{D}$ printing [18,21]. These scaffolds showed homogeneous macroporosity (approx. 500 microns) and bulk open porosity approx. $70 \%[18,21]$.

For its simplicity and no need of highly technical tools, TIPS represents an attractive strategy to tailor the structure of highly porous polymer scaffolds filled with great amounts of inorganic powders, which would negatively affect the melt rheology of PCL, making its processability very difficult through using solution and melt-based additive manufacturing techniques.

In our study, PCL scaffolds doped with $\mathrm{CaSi}$ and $\mathrm{CaP}$ produced by TIPS allowed the preparation of highly porous structures containing considerable amounts of mineral fillers (up to $20 \% \mathrm{wt}$ ). The high porosity values obtained (approaching 95\%, Table 1) did not induce relevant brittleness in the materials, that retained the possibility to be easily handled during characterization tests, without risk of collapse. The viscoelastic properties analyzed in compression mode using DMTA (Table 3) were consistent with the values previously reported in literature for analogous PCL-based porous systems [32]. The reinforcing and nucleating action of the inorganic fillers CaSi and DCPD on PCL matrix were confirmed by the increased value of storage modulus for all the composites, and from the slight increase in the crystallization temperature. When the inorganic particles were loaded at the highest amount in PCL-10CaSi-10DCPD scaffold, a detrimental effect on the mechanical properties was observed (Table 5), probably due to particles agglomeration as a consequence of the high loading. However, both vibrational and DSC results showed that the presence of the doping agents in the different scaffold formulations did not substantially affect the polymer structure, which remained semi-crystalline. Actually, by comparing the pure PCL and composite scaffolds, the DSC and Raman techniques did not detect significantly different $\chi c$ (\%) (Table 2), $\mathrm{I}_{1419 \text { (PCL C) }} / \mathrm{I}_{1443(\mathrm{PCL} C+\mathrm{A})}$ and $\mathrm{I}_{1285(\mathrm{PCL}}$

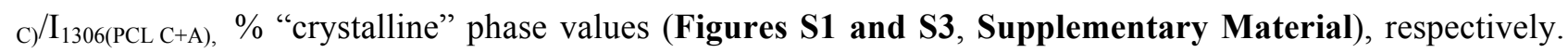
In other words, the presence of the mineral doping agents neither favors PCL crystallization (acting as nucleating sites [39,40] nor hinders polymer crystallization [41-45].

Limits of the designed mineral-doped scaffolds may be the low mechanical properties. However, in maxillofacial surgery, scaffolds may be positioned in non-load-bearing sites or in temporarily unloaded sites during healing, allowing the bone tissue regeneration through the scaffold which will be slowly replaced by new bone tissue. Similarly, conventional oral rehabilitation protocols shows that loading procedures should be post-poned for several months, waiting for new bone formation [Gallucci 2018]. The needed mechanical strength is to maintain their integrity and avoid tissue collapse or filling with fibrous tissue until complete tissue regeneration [Loh 2013].

The mineral-doped scaffolds were able to release biologically relevant ions $(\mathrm{OH}$ and $\mathrm{Ca})$, creating the conditions of a bone forming osteoblastic microenvironment. The initial marked alkalinizing ability of the 
mineral-doped scaffolds (approx. $\mathrm{pH}$ 9) triggers/favours the early $\mathrm{CaP}$ nucleation on the scaffold surface [Gandolfi 2010]. Hydroxide ions stimulate the release of alkaline phosphatase and BMP-2 which participates in the mineralization processes [Estrela 1995; Okabe 2006].

Moreover, the alkaline $\mathrm{pH}$ created in the first days may also confer a slight antibacterial activity (enzymatic inhibition of microorganisms), that may be useful early after the treatment. HCSC antimicrobial properties are well-known in literature $[4,67]$.

Ca ions from CaSi and HCSC powders are soluble molecular signals which trigger the cascade of cells differentiation into osteblastic cell lines [Ripamonti 2009, Jung 2010]. In particular osteopontin, bone sialoprotein [Jung 2010], bone morphogenic protein-2 (BMP-2) and alkaline phosphatase are modulated by increasing concentrations of extracellular $\mathrm{Ca}$ ions [68].

$\mathrm{SiOH}$ silanol groups form owing to the hydration of calcium silicates particles. At alkaline $\mathrm{pH}$, the deprotonation of $\mathrm{SiOH}$ groups should predominate with the consequent formation of $\mathrm{SiO}$ - groups that acts as nucleating sites for the formation of apatite crystals [5]. Neo angiogenesis processes are also stimulated by the presence of $\mathrm{Si}$ ions in HCSC through the increased gene expression of pro-angiogenic cytokines (such vascular endothelial growth factor) and nitric oxide synthasis [69-71].

A CaP layer was present on all the mineral doped scaffolds; FT-Raman and micro-Raman spectroscopy showed that, among the analyzed scaffolds, the sample containing the highest amounts of CaSi and DCPD, i.e. PCL-10CaSi-10DCPD, formed the thickest deposit, as expectable on the basis of its highest release of calcium ions (Table 4) and its highest alkalinizing activity (Table 5), and as the presence of CaP in addition to CaSi, accelerates the apatite nucleation by calcium silicates [10]. Actually, the FT-Raman spectra of this sample displayed the highest decrease in fluorescence upon soaking in HBSS (Figure 10a); this spectral feature may be used to qualitatively estimate the thickness of the deposit. In fact, the thicker the deposit, the highest is the masking effect of the fluorescence produced by the cement underneath. At the same time, for the PCL-10CaSi-10DCPD scaffold, micro-Raman spectroscopy revealed the highest increases in the $\mathrm{I}_{959(\mathrm{Ap}+\mathrm{PCL})} / \mathrm{I}_{1443(\mathrm{PCL})}$ and $\mathrm{I}_{959(\mathrm{Ap}+\mathrm{PCL})} / \mathrm{I}_{1306(\mathrm{PCL})}$ intensity ratios (Figure 10c). Surface porosity evaluation showed that $\mathrm{CaP}$ deposition counterbalanced the increase of porosity attributable to PCL degradation.

Considering the mineral layer, atomic $\mathrm{Ca} / \mathrm{P}$ ratio varied among the mineral-doped scaffolds. The $\mathrm{CaP}$ layer was mostly constituted by non-stoichiometric apatite (Ca/P around 1.67) [46] on PCL-10CaSi and PCL5CaSi-5DCPD. Micro-Raman spectroscopy showed that the deposit formed on the former was mainly composed of calcite; actually, EDX revealed a $\mathrm{Ca} / \mathrm{P}>2.0$ for some areas of this aged sample.

Concerning PCL-10CaSi-10DCPD, micro-Raman spectroscopy revealed that the deposit formed on this scaffold was mainly composed of B-type carbonated apatite (Figure 10b and Figure S6, Supplementary Material); the $\mathrm{Ca} / \mathrm{P}$ value measured by $\mathrm{EDX}$ on the entire area was 1.78 , consistently with the micro-Raman findings. At this purpose, it may be recalled that micro-Raman spectroscopy has been widely proposed as technique of choice to detect B-type carbonated apatites in the investigation of physiological and 
pathological mineralization processes [S. J. Smith, R. Emery, A. Pitsillides, C. E. Clarkin, S. Mahajan. Detection of early osteogenic commitment in primary cells using Raman spectroscopy. Analyst, 2017, 142, 1962-1973. W. R. Lloyd, S. Agarwal, S. U. Nigwekar, K. Esmonde-White, S. Loder, S. Fagan, J. Goverman, B. R. Olsen, D. Jumlongras, M. D. Morris, B. Levi. Raman spectroscopy for label-free identification of calciphylaxis. Journal of Biomedical Optics (2015) Vol. 20(8). 080501/1- 080501/3. C. P. Tarnowski, M. A. Ignelzi Jr., M. D. Morris. Mineralization of Developing Mouse Calvaria as Revealed by Raman Microspectroscopy Journal Of Bone And Mineral Research 17, (2002). B. Wopenka, * A. Kent, J. D. Pasteris, Y. Yoon, S. Thomopoulos. The Tendon-to-Bone Transition of the Rotator Cuff: A Preliminary Raman Spectroscopic Study Documenting the Gradual Mineralization Across the Insertion in Rat Tissue Samples. Applied Spectroscopy 62, 2008, 1285-94. G. Penel, C. Delfosse, M. Descamps, G. Leroy. Composition of bone and apatitic biomaterials as revealed by intravital Raman microspectroscopy Bone 36 (2005) 893 - 901.].

It is interesting to note that the composite samples formed a relatively thin deposit; actually, the bands of the polymer underneath were still detectable, differently from the corresponding samples prepared using poly(Llactic acid) (PLLA) as polymeric component [9]. The composite PCL-based samples formed a thinner deposit and released less calcium ions than the previously analyzed PLA-based scaffolds [9]; this result is not unexpected since it is well known that PCL is a more hydrophobic polymer than PLLA. For the scaffolds investigated in this study, the lower hydrophilicity of the polymeric matrix slowed down the hydration reaction of the cement and thus calcium release. Therefore, it is not surprising that they displayed a lower apatite forming ability than their PLLA analogues.

Micro-Raman analyses showed that also the pure PCL scaffolds nucleated apatite on their surface (Figure 4); this result is in agreement with the ESEM observations (Figure 3), which showed a noticeable decrease in pore sizes and porosity as a consequence of apatite deposition. An analogous apatite forming ability was observed for PLLA scaffolds [9]. Some studies have reported that PCL has no apatite forming ability [41,4850], while others have found an opposite behavior, often by using more concentrated simulated body fluid solutions [51-54]. These contradicting results suggest, as previously reported [9] that the chemical and physical properties of the sample (i.e. the physical form and porosity) play a crucial role in mineralization experiments.

Whilst pure PCL scaffolds underwent a general decrease in porosity upon soaking in HBSS, the composite devices showed an opposite behaviour (see in particular the PCL-5CaSi-5DCPD), suggesting that polymer degradation and leaching of the mineral doping agents due to hydrolysis prevailed over apatite deposition. This different behaviour does not appear surprising. At this purpose, it must be recalled that the biodegradation rate of a polymer mainly depends on its intrinsic properties that control water accessibility to the ester linkages (i.e. those susceptible to hydrolysis): composition, hydrophilicity/hydrophobicity, surface area, morphology (crystalline/amorphous), glass transition temperatures, molecular weight $[55,56]$. The presence of the mineral doping agents should increase the degradation rate for several reasons. According to other studies $[41,43,47,51]$, their hydrophilicity as well as the increase in the surface area they produce should allow the water molecules to penetrate more easily within the materials and to cause their hydrolytic 
degradation. Moreover, it must be stressed that the CaSi hydration reactions produce an alkaline $\mathrm{pH}$ (Table 5), which is known to accelerate the hydrolysis of aliphatic polyesters such as PCL [25,57-59].

Upon ageing in HBSS, a certain crystallinity decrease (i.e. in the $\mathrm{I}_{1419(\mathrm{PCL})} / \mathrm{I}_{1443 \text { (PCL C+A) }}$ and $\mathrm{I}_{1285(\mathrm{PCL} \text { C) }} / \mathrm{I}_{1306(\mathrm{PCL}}$ $\mathrm{C}+\mathrm{A})$ intensity ratios and \% "crystalline" phase) occurred in pure PCL scaffolds, as revealed by vibrational spectroscopy (Figures S1 and S3, Supplementary Material). At this purpose, it must be recalled that in semicristalline PCL polymers, an increase in crystallinity upon degradation has been often reported [58,6063] and explained as a result of the fragmentation of the polymers into shorter chains which are more able to pack in a crystalline structure, or in terms of the preferential removal of the more easily degradable amorphous regions of the polymer, leading to an enrichment in crystalline domains. However, some studies have reported different trends and analogous decreases in crystallinity have been reported also by other authors for pure PCL $[64,65]$ and composite calcium phosphate containing PCL-based devices $[45,66]$. For pure PCL samples, they have been explained by considering that degradation takes place not only in the amorphous phase, but also in the crystalline region, and the latter is converted to an imperfect crystal structure; for the composites, the mineral particles have been hypothesized to act as obstructions to the crystallization of the PCL chains. On the other hand, Raman spectroscopy showed that upon ageing in HBSS, no significant changes in polymer crystallinity (i.e. in the $\mathrm{I}_{1419(\mathrm{PCL})} / \mathrm{I}_{1443(\mathrm{PCL} \mathrm{C}+\mathrm{A})}$ and $\mathrm{I}_{1285(\mathrm{PCL})} / \mathrm{I}_{1306(\mathrm{PCL} \mathrm{C}+\mathrm{A})}$ intensity ratios) occurred. This result may be explained in relation to the findings by Žuckiene et al. [43], who have reported that the addition of montmorillonite to PCL-based polyurethanes, while allowing the water molecules to penetrate more easily within the materials, retards the rate of crystallinity change during degradation.

The in vitro biocompatibility of the designed scaffolds was assessed quantitatively by measuring cell viability and proliferation. The results confirmed the lack of toxicity for all the investigated samples (Figure 11). PCL-10CaSi-10DCPD resulted to be the most promising in sustaining a good cell proliferation during the first 7 days of culture, with a further increase at 14 days (Figure 11). Investigations of cell morphology and cytoskeleton organization of Balb/3T3 cultured on the scaffolds after 14 days confirmed the quantitative data and revealed the presence of Balb/3T3 cells on all the investigated samples (Figure 12). The presence of a good degree of cell colonization of scaffolds is confirmed by the visualization and distribution of cell nuclei (Figure 12). Representative images of cells grown onto PCL-10CaSi-10DCPD samples displayed a consistent F-actin organization with stress fibers well stretched along the cytoplasm, thus corroborating the possibility of the developed scaffolds to act as synthetic extracellular matrix for cell adhesion and proliferation (Figure 13).

\section{Conclusions}

Key findings of this research may be summarized as follows:

- PCL is a suitable matrix for the production of mineral-doped scaffolds that allow the nucleation of CaP and apatite on their surface; 
- TIPS fabrication technique allowed to produce highly porous PCL-based scaffolds (porosity approaching 95\%), doped with considerable amounts of mineral fillers (up to $20 \mathrm{wt} \%$ );

- the incorporation of reactive hydrophilic CaSi and DCPD minerals allows to create biointeractive $\left(\mathrm{Ca}^{++}\right.$and $\mathrm{OH}^{-}$ion release), bioactive (apatite nucleation) and biocompatible scaffolds, overcoming PCL disadvantages (hydrophobicity, release of acid degradation products and reduced cell adhesion and growth).

- the developed mineral-doped scaffolds may act synthetic extracellular matrices for cell adhesion and proliferation, and could have a potential role in the activation of mineralizing cells bone regeneration procedures.

Interestingly, by using TIPS technique the shape of the scaffolds may be designed according to the donor site shape, as the fabrication of the scaffold initiates from a liquid suspension that can be adapted to any desired mold.

\section{References}

1. Kriebel K, Hieke C, Müller-Hilke B, Nakata M, Kreikemeyer B. Oral biofilms from symbiotic to pathogenic interactions and associated disease-connection of periodontitis and rheumatic arthritis by peptidylarginine deiminase. Front Microbiol. 2018;30;9:53.

2. Oryan A, Alidadi S, Moshiri A, Maffulli N. Bone regenerative medicine: classic options, novel strategies, and future directions. J Orthop Surg Res 2014;17:1-27.

3. Vallittu PK. Bioactive glass-containing cranial implants: an overview. J Mater Sci 2017 52:8772-8784.

4. Prati C \& Gandolfi MG Calcium silicate bioactive cements: biological perspectives and clinical applications. Dental Materials 2015;31:351-370

5. Gandolfi MG, Siboni F, Botero T, Bossù M, Riccitiello F, Prati C. Calcium silicate and calcium hydroxide materials for pulp capping: Biointeractivity, porosity, solubility and bioactivity of current formulations. J Appl Biomater Funct Mater 2015;13:1-18.

6. Siboni F, Taddei P, Zamparini F, Prati C, Gandolfi MG Properties of BioRoot RCS, a tricalcium silicate endodontic sealer modified with povidone and polycarboxylate. Int Endod J 2017;50:120-136.

7. Zhou W, Zheng Q, Tan X, Song D, Zhang L, Huang D. Comparison of mineral trioxide aggregate and iRoot BP plus root repair material as root-end filling materials in endodontic microsurgery: a prospective randomized controlled study. J Endod 2017;43:1-6.

8. Gandolfi MG, Spagnuolo G, Siboni F, Procino A, Rivieccio V, Pelliccioni GA, Prati C, Rengo S Calcium silicate/calcium phosphate biphasic cements for vital pulp therapy: chemical-physical properties and human pulp cells response. Clinical Oral Investigations 2015;19:2075-2089.

9. Gandolfi MG, Zamparini F, Degli Esposti M, Chiellini F, Aparicio C, Fava F, Prati C. Polylactic acid-based porous scaffolds doped with calcium silicate and dicalcium phosphate dihydrate designed for biomedical application. Mater Sci Eng C 2018;82:163-181. 
10. Gandolfi MG, Taddei P, Tinti A, De Stefano Dorigo E, Prati C. Alpha-TCP improves the apatite-formation ability of calcium-silicate hydraulic cement soaked in phosphate solutions. Mater Sci Eng C 2011;31:1412-1422.

11. Zheng C, Gao H, Yang D-, Liu M, Cheng H, Wu Y-, et al. PCL-based thermo-gelling polymers for in vivo delivery of chemotherapeutics to tumors. Mater Sci Eng C 2017;74:110-116.

12. Marei NH, El-Sherbiny IM, Lotfy A, El-Badawy A, El-Badri N. Mesenchymal stem cells growth and proliferation enhancement using PLA vs PCL based nanofibrous scaffolds. Int J Biol Macromol 2016;93:9-19

13. Woodruff MA, Hutmacher DW. The return of a forgotten polymer-Polycaprolactone in the 21 st century Prog Polym Sci 2010;35:1217-1256.

14. Ambre AH, Katti DR, Katti KS. 2015. Biomineralized hydroxyapatite nanoclay composite scaffolds with polycaprolactone for stem cell-based bone tissue engineering. J Biomed Mater Res Part A 2015:103A:2077-2101.

15. Kweon H, Yoo M, Park I, Kim T, Lee H, Lee S, et al. A novel degradable polycaprolactone network for tissue engineering. Biomaterials 2003;24:801-808.

16. Shor L, Güçeri S, Wen X, Gandhi M, Sun W. Fabrication of three-dimensional polycaprolactone/hydroxyapatite tissue scaffolds and osteoblast-scaffold interactions in vitro. Biomaterials 2007;28:5291-5297.

17. Causa F, Netti PA, Ambrosio L, Ciapetti G, Baldini N, Pagani S, et al. Poly-e-caprolactone/hydroxyapatite composites for bone regeneration: in vitro characterization and human osteoblast response. J Biomed Mater Res A 2005;76A:151-62.

18. Chiu YC, Fang HY, Hsu TT, Lin CY, Shie MY. The Characteristics of Mineral Trioxide Aggregate/Polycaprolactone 3-dimensional Scaffold with Osteogenesis Properties for Tissue Regeneration. J Endod 2017;43:923-929.

19. Cho YS, Hong MW, Quan M, Kim SY, Lee SH, Lee SJ, Kim YY, Cho YS. Assessments for bone regeneration using the polycaprolactone SLUP (salt-leaching using powder) scaffold. J Biomed Mater Res A 2017;12:3432-3444.

20. Fabbri P, Cannillo V, Sola A, Dorigato A, Chiellini F. Highly porous polycaprolactone-45S5 Bioglass ${ }^{\circledR}$ scaffolds for bone tissue engineering. Compos Sci Technol 2010;70:1869-1878.

21. Ho CC, Fang HY, Wang B, Huang TH, Shie MY. The effects of Biodentine/polycaprolactone three-dimensionalscaffold with odontogenesis properties on human dental pulp cells. Int Endod J 2018 ;51:291-300.

22. Nelson DG, Featherstone JD. Preparation, analysis, and characterization of carbonated apatites. Calcif Tissue Int 1982;34:69-81.

23. Kister G, Cassanas G, Bergounhon M, Hoarau D, Vert M. Structural characterization and hydrolytic degradation of solid copolymers of D,L-lactide-co-e-caprolactone by Raman spectroscopy. Polymer 2000;41:925-932.

24. Taddei P, Tinti A, Reggiani M, Fagnano C. In vitro mineralization of bioresorbable poly(c-caprolactone)/apatite composites for bone tissue engineering: a vibrational and thermal investigation. J Mol Struct 2005;744-747:135-143.

25. Taddei P, Di Foggia M, Causa F, Ambrosio L, Fagnano C. In vitro bioactivity of poly( $\varepsilon$-caprolactone)-apatite (PCLAP) scaffolds for bone tissue engineering: the influence of the PCL/AP ratio. Int J Artif Organs 2006;29:719-725.

26. Di Foggia M, Corda U, Plescia E, Taddei P, Torreggiani A. Effects of sterilisation by high-energy radiation on biomedical poly-(E-caprolactone)/hydroxyapatite (PCL/HA) composites. J Mater Sci Mater Med 2010;21:1789-1797.

27. Guarino V, Cirillo V, Taddei P, Alvarez-Perez MA, Ambrosio L. Tuning size scale and crystallinity of PCL electrospun fibres via solvent permittivity to address hMSC response. Macromol Biosci 2011;11:1694-1705.

28. Castilla Bolaños MA, Buttigieg J, Briceño Triana JC. Development and characterization of a novel porous small intestine submucosa-hydroxyapatite scaffold for bone regeneration. Mater Sci Eng C 2017;72:519-525 
29. Potgieter-Vermaak SS, Potgieter JH, Van Grieken R. The application of Raman spectrometry to investigate and characterize cement, Part I: A review. Cem Concr Res 2006;36:656-662

30. Conjeaud M, Boyer H. Some possibilities of Raman microprobe in cement chemistry. Cem Concr Res 1980;10:6170 .

31. Crescenzi V, Manzini G, Calzalari G, Borri C. Thermodynamics of fusion of poly- $\beta$-propiolactone and poly- $\epsilon-$ caprolactone. comparative analysis of the melting of aliphatic polylactone and polyester chains Eur Polym J 1972;8: 449-463.

32. Tang M, Purcell M, Steele JAM Lee KY, McCullen S, Shakesheff KM, Bismark A, Stevens MM, Howdle SM, Williams CK. Porous copolymers of e-PCL as scaffolds for tissue engineering, Macromolecules 2013; 46:8136-8143

33. Park CH, Rios HF, Jin Q, Bland ME, Flanagan CL, Hollister SJ, Giannobile WV. Biomimetic hybrid scaffolds for engineering human tooth-ligament interfaces. Biomaterials 2010;31:5945-5952.

34. Wongsupa N, Nuntanaranont T, Kamolmattayakul S, Thuaksuban N. Assessment of bone regeneration of a tissueengineered bone complex using human dental pulp stem cells/poly( $\varepsilon$-caprolactone)-biphasic calcium phosphate scaffold constructs in rabbit calvarial defects. J Mater Sci Mater Med 2017; 28:77. doi: 10.1007/s10856-017-5883-x

35. Huang SH, Hsu TT, Huang, TH, Lin CY, Shie MY. Fabrication and characterization of polycaprolactone and tricalcium phosphate composites for tissue engineering applications. J Dent Sci 2017;12:33-43

36. Lin J, Zeng Q, Wei X, Zhao W, Cui M, Gu J, Lu J, Yang M, Ling J. Regenerative Endodontics Versus Apexification in Immature Permanent Teeth with Apical Periodontitis: A Prospective Randomized Controlled Study. J Endod 2017; 17:30810-30815.

37. Sánchez-Salcedo S, Nieto A, Vallet-Regí M, Hydroxyapatite/ $\beta$-tricalcium phosphate/ agarose macroporous scaffolds for bone tissue engineering. Chem Eng J 2008;137:62-71.

38. Perez RA, Mestres G. Role of pore size and morphology in musculo-skeletal tissue regeneration, Mater Sci Eng C 2016;61:922-939.

39. Neppalli R, Causin V, Marega C, Saini R, Mba M, Marigo A. structure, morphology, and biodegradability of Poly( $\varepsilon$-caprolactone)-based nanocomposites. Polym Eng Sci 2011;51:1489-1496.

40. Koupaei N, Karkhaneh A, Daliri Joupari M. Preparation and characterization of (PCL-crosslinkedPEG)/hydroxyapatite as bone tissue engineering scaffolds. J Biomed Mater Res Part A 2015;103: 3919-3926.

41. Lin YH, Chiu YC, Shen YF, Wu YHA, Shie MY. Bioactive calcium silicate/poly- $\varepsilon$-caprolactone composite scaffolds 3D printed under mild conditions for bone tissue engineering. J Mater Sci: Mater Med 2018; 29:11 DOI 10.1007/s10856-017-6020-6.

42. Dziadek M, Pawlik J, Menaszek E, Stodolak-Zych E, Cholewa-Kowalska K. Effect of the preparation methods on architecture, crystallinity, hydrolytic degradation, bioactivity, and biocompatibility of PCL/bioglass composite scaffolds. J Biomed Mater Res Part B: Appl Biomater 2015;103B: 1580-1593.

43. Žukiene K, Jankauskaite V, Betingyte V, Baltusnikas A. Properties of Recycled Polycaprolactone-Based Thermoplastic Polyurethane Filled with Montmorillonites. J Appl Polym Sci 2013;128: 2186-2196.

44. Romeo V, Gorrasi G, Vittoria V. Encapsulation and exfoliation of inorganic lamellar fillers into polycaprolactone by electrospinning. Biomacromolecules 2007; 8:3147-3152.

45. Lam CXF, Savalani MM, Teoh SH, Hutmacher DW. Dynamics of in vitro polymer degradation of polycaprolactone-based scaffolds: accelerated versus simulated physiological conditions. Biomed Mater 2008;3: 034108 doi:10.1088/1748-6041/3/3/034108.

46. Gandolfi MG, Taddei P, Modena E, Siboni F, Prati C Biointeractivity-related versus chemi/physisorption-related apatite precursor-forming ability of current root end filling materials. J Biomed Mater Res B Appl Biomater 2013;101:1107-1123. 
47. Diba M, Kharaziha M, Fathi MH, Gholipourmalekabadi M, Samadikuchaksaraei A. Preparation and characterization of polycaprolactone/forsterite nanocomposite porous scaffolds designed for bone tissue regeneration. Compos Sci Technol 2012;72:716-723.

48. Gupta KK, Kundan A, Mishra PK, Srivastava P, Mohanty S, Singh NK, Mishra A, Maiti P. Polycaprolactone composites with $\mathrm{TiO}_{2}$ for potential nanobiomaterials: tunable properties using different phases. Phys Chem Chem Phys 2012;14:12844-12853.

49. Cheng YL, Chen YW, Wangde K, Shie MY. Enhanced adhesion and differentiation of human mesenchymal stem cell inside apatite mineralized/poly(dopamine)-coated poly(E-caprolactone) scaffolds by stereolithography. J Mater Chem B 2016; 4:6307-6315.

50. Heydari Z, Mohebbi-Kalhori D, Afarani MS. Engineered electrospun polycaprolactone (PCL)/octacalcium phosphate (OCP) scaffold for bone tissue engineering. Mater Sci Eng C Mater Biol Appl 2017;81:127-132.

51. Khoshroo K, Jafarzadeh Kashi TS, Moztarzadeh F, Tahriri M, Jazayeri HE, Tayebi L. Development of 3D PCL microsphere/TiO2 nanotube composite scaffolds for bone tissue engineering. Mat Sci Eng C 2017;70:586-598.

52. Gerçek Beşkardeş I, Gümüşderelioğlu M. Biomimetic apatite-coated PCL scaffolds: effect of surface nanotopography on cellular functions. J Bioact Compat Polym 2009; 24:507-524.

53. Park SA, Lee JB, Kim YE, Kim JE, Lee JH, Shin JW, Kwon IK, Kim WD. Fabrication of biomimetic PCL scaffold using rapid prototyping for bone tissue engineering. Macromolecular Research 2014; 22:882-887.

54. Suryavanshi A, Khanna K, Sindhu KR, Bellare J, Srivastava R. Magnesium oxide nanoparticle-loaded polycaprolactone composite electrospun fiber scaffolds for bone-soft tissue engineering applications: in-vitro and invivo evaluation. Biomed Mater 2017;12: 055011 doi: 10.1088/1748-605X/aa792b.

55. Langer R in: Kahn J, Ratner BD, Hoffmann AS, Schoen FJ, Lemons JE (Eds.), Biomaterials Science. An Introduction to Materials in Medicine, Academic Press, San Diego, 1996, p. 64.

56. Vert M, Li SM, Splenlehauer G, Guerin P. Bioresorbability and biocompatibility of aliphatic polyesters, J Mater Sci Mater Med 1992; 3:432-446

57. Lam CXF, Savalani MM, Teoh SH, Hutmacher DW. Dynamics of in vitro polymer degradation of polycaprolactone-based scaffolds: accelerated versus simulated physiological conditions. Biomed Mater 2008;3 034108. doi: 10.1088/1748-6041/3/3/034108

58. Taddei P, Tinti A, Fini G. Vibrational spectroscopy of polymeric biomaterials. J Raman Spectrosc. 2001; 32: 619629.

59. Taddei P, Simoni R, Fini G. Spectroscopic study on the in vitro degradation of a biodegradable composite periodontal membrane. J Mol Struct 2011;565-566: 317-322.

60. Rutkowska M, Dereszewska A, Jastrzębska M, Janik H. Biodegradation of polycaprolactone in plant treatment active sludge. Macromol Sympos 1998;130:199-204.

61. Lam CHF, Hutmacher DW, Schantz JT, Woodruff MA, Teoh SH. Evaluation of polycaprolactone scaffold degradation for 6 months in vitro and in vivo. J Biomed Mater Res 2009;90: 906-919.

62. Yoshioka T, Kamada F, Kawazoe N, Tateishi T, Chen G. Structural changes and biodegradation of PLLA, PCL, and PLGA sponges during In vitro incubation. Polym Eng Sci 2010;50:1895-1903.

63. Chen DR, Bei JZ, Wang G. Polycaprolactone microparticles and their biodegradation. Polym Degrad Stab 2000, 67, 455-459.

64. Gan Z, Liang Q, Zhang J, Jing X. Enzymatic degradation of poly( $\varepsilon$-caprolactone) film in phosphate buffer solution containing lipases. Polym Degrad Stab 1997;56:209-213. 
65. Hermanova S, Balkova R, Voberkova S, Chamradova I, Omelkova J, Richtera L, Mravcova L, Jancar J. biodegradation study on Poly( $\varepsilon$-caprolactone) with bimodal molecular weight distribution. J Appl Polym Sci 2013; 127 : 4726-4735.

66. Wang Y, Liu L, Guo. Characterization of biodegradable and cytocompatible nano-hydroxyapatite/polycaprolactone porous scaffolds in degradation in vitro. Polym Degrad Stab 2010; 95:207-213.

67. Lovato KF, Sedgley CM. Antibacterial activity of endosequence root repair material and proroot MTA against clinical isolates of Enterococcus faecalis. J Endod. 2011;37:1542-1546

68. Sun J, Wei L, Liu X, Li J, Li B, Wang G, Meng F. Influences of ionic dissolution products of dicalcium silicate coating on osteoblastic proliferation, differentiation and gene expression. Acta Biomater 2009;5:1284-1293.

69. Paranjpe A, Zhang H, Johnson JD. Effects of mineral trioxide aggregate on human dental pulp cells after pulpcapping procedures. J Endod 2010;36:1042-1047.

70. Wang S, Wang X, Draenert FG, Albert O, Schröder HC, Mailänder V, Mitov G, Müller WE. Bioactive and biodegradable silica biomaterial for bone regeneration. Bone 2014;67:292-304.

71. Zhai W, Lu H, Chen L, Lin X, Huang Y, Dai K, Naoki K, Chen G, Chang J. Silicate bioceramics induce angiogenesis during bone regeneration. Acta Biomater 2012;8:341-349.

Gandolfi MG, Iezzi G, Piattelli A, Prati C, Scarano A. Osteoinductive potential and bone-bonding ability of ProRoot MTA, MTA Plus and Biodentine in rabbit intramedullary model: Microchemical characterization and histological analysis. Dent Mater 2017;33:221-238.

Gandolfi MG, Shah SN, Feng R, Prati C, Akintoye SO. Biomimetic calcium-silicate cements support differentiation of human orofacial mesenchymal stem cells. J Endod 2011;37:1102-1108

Gandolfi MG, Ciapetti G, Taddei P, Perut F, Tinti A, Cardoso MV, Van Meerbeck B, Prati C. Apatite formation on bioactive calcium-silicate cements for dentistry affects surface topography and human marrow stromal cells proliferation. Dent Mater 2010;26:974-992.

Karageorgiou V, Kaplan D. Porosity of 3D biomaterial scaffolds and osteogenesis. Biomaterials 2005;26:5474-91.

Loh QL, Choong C. Three-dimensional scaffolds for tissue engineering applications: role of porosity and pore size. Tissue Eng Part B Rev. 2013;19:485-502.

Rashid F, Shiba H, Mizuno N, et al. The effect of extracellular calcium ion on gene expression of bone-related proteins inhuman pulp cells. J Endod 2003;29:104-107

Ma S, Yang Y, Carnes DL, Kim K, Park S, Oh SH, Ong JL. Effects of Dissolved Calcium and Phosphorous on Osteoblast Responses, J Oral Implantol 2005;31:61-67.

Amini AR, Adams DJ, Laurencin CT, Nukavarapu SP. Optimally porous and biomechanically compatible scaffolds for large-area bone regeneration. Tissue Eng Part A 2012;18:1376-88.

Chen G, Ushida T, Tateishi T. Poly(DL-lactic-co-glycolic acid) sponge hybridized with collagen microsponges and deposited apatite particulates. J Biomed Mater Res 2001;57:8-14.

Roy TD, Simon JL, Ricci JL, Rekow ED, Thompson VP, Parsons JR. Performance of degradable composite bone repair products made via three-dimensional fabrication techniques. J Biomed Mater Res A 2003; 66:283-91.

PAS 132 : 2007 Terminology for the bio-nano interface. British Standards Institution.

Feng B, Jinkang Z, Zhen W, Jianxi L, Jiang C, Jian L, Guolin M, Xin D. The effect of pore size on tissue ingrowth and neovascularization in porous bioceramics of controlled architecture in vivo. Biomed Mater. 2011;6:015007.

Gallucci GO, Hamilton A, Zhou W, Buser D, Chen S. Implant placement and loading protocols in partially edentulous patients: A systematic review. Clin Oral Implants Res 2018;29:106-134. 
Gandolfi MG, Taddei P, Tinti A, De Dorigo ES, Rossi PL, Prati C. Kinetics of apatite formation on a calcium-silicate cement for root-end filling during ageing in physiological-like phosphate solutions. Clin Oral Invest 2010;14:659-668.

Estrela C, Sydney GB, Bammann LL, Felippe Júnior O. Mechanism of action of calcium and hydroxyl ions of calcium hydroxide on tissue and bacteria. Braz Dent J 1995;6(2):85-90.

Okabe T, Sakamoto M, Takeuchi H, Matsushima K. Effects of pH on mineralization ability of human dental pulp cells. J Endod 2006;32(3):198-201.

Ripamonti, U. Biomimetism, biomimetic matrices and the induction of bone formation. Journal of Cellular and Molecular Medicine 2009;13:2953-2972.

Nakamura S, Matsumoto T, Sasaki J, Egusa H, Lee KY, Nakano T, Sohmura T, Nakahira A (2010) Effect of calcium ion concentrations on osteogenic differentiation and hematopoietic stem cell nicherelated protein expression in osteoblasts. Tissue Eng Part A 16: 2467-2473. 


\section{Figure Legends}

Table 1 - Open porosity (\%), porous scaffold density ( $\mathrm{g} \mathrm{cm}-3)$ and filler weight content (wt \%) of PCLbased scaffolds (mean $\pm \mathrm{SD}$ ).

Table 2 - Melting Temperatures, Enthalpy of Melting, Crystallization Temperature, Enthalpy of Crystallization, and Crystallinity Percentage of PCL-based scaffolds.

Table 3 - Dynamic mechanical thermal properties of PCL-based scaffolds.

Table 4 - The release of Ca release (mean $\pm \mathrm{SD}$, expressed in ppm) evaluated at six endpoints. Calcium released from PCL samples was irrelevant. The highest cumulative calcium release was observed for PCL10CaSi-10DCPD.

Table 5 - The $\mathrm{pH}$ of soaking water (mean $\pm \mathrm{SD}$ ) evaluated at 3, 24 hours, 3, 7, 14 and 28 days. pH values were statistically higher for mineral doped scaffolds with respect to PCL traditional scaffold up to 1 day $(\mathrm{p}<0.05)$. After that $\mathrm{pH}$ values were similar to pure PCL and deionized water.

Figure 1 - Time line protocol of Thermally-Induced phase separation (TIPS) technique used in this study.

Figure 2 - PCL mineral-doped scaffold produced by using TIPS.

Figure 3 - ESEM surface micromorphology and EDX spectra of the PCL scaffold before (i.e. fresh) and after 28 days in HBSS (500× and 1000× magnifications). An irregular porous structure was present with large pores, ranging from 20 to $200 \mu \mathrm{m}$. After 28 days immersion in HBSS, a uniform rough surface with small circular pores, ranging from 10-20 $\mu$ m (smaller than that of fresh samples) was present. EDX on fresh samples revealed PCL constitutional peaks (C, O). After 28 days in HBSS, EDX showed besides constitutional peaks $(\mathrm{C}, \mathrm{O})$ also the presence of $\mathrm{Na}$ and $\mathrm{Cl}$ (from HBSS)

Figure 4 - FT-Raman (a) and micro-Raman (b) average spectra recorded at a 100× magnification on the surface of the PCL scaffold before (i.e. fresh, black line) and after ageing in HBSS for 28 days (red line). The bands prevalently assignable to crystalline (C) and amorphous (A) PCL polymer as well as apatite (Ap) are indicated. (c) Trend of the $\mathrm{I}_{959(\mathrm{Ap}+\mathrm{PCL})} / \mathrm{I}_{1443(\mathrm{PCL})}$ and $\mathrm{I}_{959(\mathrm{Ap}+\mathrm{PCL})} / \mathrm{I}_{1306(\mathrm{PCL})}$ intensity ratios (average \pm standard deviation) as calculated from the micro-Raman spectra of the PCL scaffolds. 
Figure 5 - ESEM surface micromorphology and EDX spectra of the PCL-10CaSi scaffold before (i.e. fresh) and after 28 days in HBSS (500× and 1000× magnifications). A honeycomb-like structure mostly composed of small circular pores (range 15-30 $\mu \mathrm{m}$ ) was observed. Small dense granules were also well-distributed on the scaffold surface. After 28 days in HBSS a layer of $\mathrm{CaP}$ was present on the scaffold structure that appeared unaltered. EDX on one granule revealed the one granule revealed the presence of $\mathrm{Ca}$ and $\mathrm{Si}$, but also traces of Aluminium (Al) and Sulphur (S). EDX after immersion in HBSS taken on the entire area revealed the constitutional elements $(\mathrm{C}, \mathrm{O})$, the appearance of $\mathrm{Na}, \mathrm{Cl}$ and $\mathrm{P}$, and a moderate increase of $\mathrm{Ca}$. Traces of Si and $\mathrm{Al}$ were also detected.

Figure 6 - FT-Raman (a) and micro-Raman (b) average spectra recorded at a $100 \times$ magnification on the surface of the PCL-10CaSi scaffold before (i.e. fresh, black line) and after ageing in HBSS for 28 days (red line). The spectrum of the CaSi cement is reported for comparison. The bands prevalently assignable to crystalline (C) and amorphous (A) PCL polymer, gypsum (G), alite (Al), belite (B), calcite (Calc) are indicated. Asterisks indicate the fluorescence bands due to the belite phase.

Figure 7 - ESEM surface micromorphology and EDX spectra of the PCL-5CaSi-5DCPD scaffold before (i.e. fresh) and after 28 days in HBSS (500× and 1000× magnifications). Fresh sample showed an irregular structure, less porous then the previous investigated samples. Some granules can be appreciated at higher magnification (arrows). After 28 days of immersion in HBSS, a honeycomb-like structure, with more regular and numerous circular pores was observed. A heterogeneous, yet constant, mineral layer can be observed on the scaffold surface also present into some pores (arrows).

EDX of fresh samples on the entire area revealed constitutional elements $(\mathrm{C}, \mathrm{O})$ and traces of Ca and P. EDX on one granule revealed the presence of $\mathrm{Ca}, \mathrm{Si}, \mathrm{Al}$ (from $\mathrm{CaSi}$ ), $\mathrm{C}$ and $\mathrm{O}$. After $28 \mathrm{~d}$ immersion in HBSS, EDX on the entire area revealed, besides the constitutional peaks $(\mathrm{C}, \mathrm{O})$ and the elements from the HBSS medium $(\mathrm{Na}, \mathrm{Cl}$ and Potassium $(\mathrm{K})$ ), the increase of $\mathrm{Ca}$ and the appearance of P. Punctual EDX on one mineral deposit revealed the marked decrease of $\mathrm{Si}$ and the marked appearance of $\mathrm{P}$ (CaP formation).

Figure 8 - FT-Raman (a) and micro-Raman (b) average spectra recorded at a 100× magnification on the surface of the PCL-5CaSi-5DCPD scaffold before (i.e. fresh, black line) and after ageing in HBSS for 28 days (red line). The bands prevalently assignable to crystalline (C) and amorphous (A) PCL polymer and apatite (Ap) are indicated. Asterisks indicate the fluorescence bands due to the belite phase. (c) Trend of the

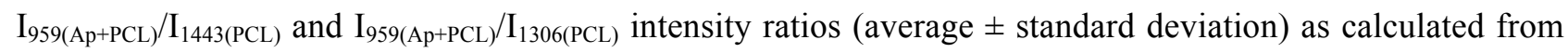
the micro-Raman spectra of the PCL-5CaSi-5DCPD scaffolds.

Figure 9 - ESEM surface micromorphology and EDX spectra of the PCL-10CaSi-10DCPD scaffold before (i.e. fresh) and after 28 days in HBSS (500× and 1000× magnifications). A porous honeycomb-like regular structure with well distributed mineral granules was observed on fresh samples. After $28 \mathrm{~d}$ immersion in 
HBSS, a mineral layer partially covered a more porous structure was observed. A great number of pores were obtruded by the mineral deposits (arrows).

EDX of fresh samples on the entire area, as well as on one granule, showed C, O (attributable to PCL structure), $\mathrm{Ca}, \mathrm{Si}, \mathrm{P}$ and $\mathrm{Al}$ (from CaSi and DCPD granules). After 28 days immersion in HBSS revealed, besides the elements attributable to the scaffold constitution $(\mathrm{C}, \mathrm{O})$ and the HBSS, the marked increase of $\mathrm{P}$ and the decrease of Si. Interestingly, punctual EDX on the deposit and revealed the marked increase of P and the disappearance of $\mathrm{Si}$.

Figure 10 - FT-Raman (a) and micro-Raman (b) average spectra recorded at a $100 \times$ magnification on the surface of the PCL-10CaSi-10DCPD scaffold before (i.e. fresh, black line) and after ageing in HBSS for 28 days (red line). The bands prevalently assignable to crystalline (C) and amorphous (A) PCL polymer and Btype carbonated apatite (Ap) are indicated. Asterisks indicate the fluorescence bands due to the belite phase. (c) Trend of the $\mathrm{I}_{959(\mathrm{Ap}+\mathrm{PCL})} / \mathrm{I}_{1443(\mathrm{PCL})}$ and $\mathrm{I}_{959(\mathrm{Ap}+\mathrm{PCL})} / \mathrm{I}_{1306(\mathrm{PCL})}$ intensity ratios (average \pm standard deviation) as calculated from the micro-Raman spectra of the PCL-10CaSi-10DCPD scaffolds.

Figure 11 - Quantitative results of cell proliferation on the experimental scaffolds and TCPS. Cell proliferation and viability was higher at 14 days than at 7 days for all the samples. PCL-10CaSi-10DCPD resulted to be the most promising in sustaining a good cell proliferation during the first 7 days of culture, with a further increase at 14 days.

Figure 12 - CLSM micrograph of cell colonization of mineral doped scaffolds. Cells nuclei were stained with DAPI. Images were captured using 10× magnification objective. After 14 days of culture, microscopic observations confirmed the quantitative data and revealed the presence of cells on all the investigated samples.

Figure 13 - CLSM visualization of F-actin cytoskeleton of cells stained with phalloidin-Alexa Fluor 488 recorded at 20× magnification, representative images of cells grown onto PCL-10CaSi-10DCPD displayed a consistent F-actin organization with stress fibers well stretched along the cytoplasm. 